NISTIR 7035

\title{
Comparison of Measured and Predicted Tracer Gas Concentrations in a Townhouse
}

\author{
Steven J. Emmerich
}

Steven J. Nabinger

Arpita Gupte

Cynthia Howard-Reed

Lance Wallace

National Institute of Standards and Technology Technology Administration, U.S. Department of Commerce 
NISTIR 7035

\title{
Comparison of Measured and Predicted Tracer Gas Concentrations in a Townhouse
}

\author{
Steven J. Emmerich \\ Steven J. Nabinger \\ Arpita Gupte \\ Cynthia Howard-Reed \\ Building Environment Division \\ Building and Fire Research Laboratory \\ National Institute of Standards and Technology
}

Lance Wallace

National Exposure Research Laboratory

U.S. Environmental Protection Agency

August 2003

\section{U.S. Department of Commerce}

Donald L. Evans, Secretary

Technology Administration

Phillip J. Bond, Undersecretary of Commerce for Technology

National Institute of Standards and Technology

Arden L. Bement, Jr., Director

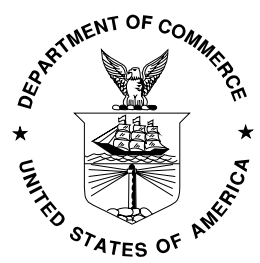




\begin{abstract}
To provide additional validation data for the multizone airflow and contaminant modeling approach (i.e., as implemented in the CONTAMW simulation program), a series of tracer gas tests were performed in an occupied three-story townhouse in Reston, Va. Tests simulated with CONTAMW consisted of short-term release of $1500 \mathrm{~mL}$ of tracer gas, sulfur hexaflouride $\left(\mathrm{SF}_{6}\right)$, within one room of the house and the measurement of $\mathrm{SF}_{6}$ concentration in 10 indoor locations. In four of the ten main test cases, the heating and air-conditioning system fan was operating. In an eleventh test case, an attic fan was operating. The location of the burst source of tracer gas included the recreation room (basement level), the kitchen/dining room (main level) and the master bedroom (upstairs level). Experiments were conducted between May 2000 and June 2001. Local ambient conditions that ranged from a low outdoor temperature of $5{ }^{\circ} \mathrm{C}$ to a high of $29^{\circ} \mathrm{C}$ and wind conditions that ranged from calm to moderate, with an average wind speed of $4 \mathrm{~m} / \mathrm{s}$, were measured and used as model inputs.
\end{abstract}

A statistical comparison of measurements and predictions was performed per ASTM Guide D5157 "Standard Guide for Statistical Evaluation of Indoor Air Quality Models" (ASTM 1997) for all cases. Guide D5157 provides statistical parameters to assess both agreement and bias and suggested criteria that model predictions should meet. Predicted and measured transient concentrations for individual zone and time-averaged zone concentrations for the whole house were compared for each test.

The results for zone average concentrations were very good with most cases meeting most or all of the D5157 criteria. For example, 9 of 10 cases met the normalized mean square error (NMSE) criteria and all cases met the normalized fractional bias (FB) criteria. Three cases did not meet the D5157 criteria for both correlation coefficient and line of regression but the discrepancy was due almost entirely to poor prediction in a single zone - the main floor bathroom. Excluding that zone resulted in these cases meeting or coming very close to meeting the D5157 criteria. For all cases, the predicted $\mathrm{SF}_{6}$ concentration averaged linearly over all zones was within $25 \%$ of the average measured concentration.

Predictions of individual zone transient concentrations were less reliable. While many cases met all the criteria, nearly half of the cases failed to meet two or more of the D5157 criteria. One factor affecting the comparison of transient concentrations was significant differences between measured and predicted peak concentrations. This difficulty is not surprising as neither the simulations nor the experiments were designed to adequately account for very short-term peaks. The report also compares predicted and measured whole house air change rates and examines the effects of weather on those rates.

Key Words: airflow modeling, building technology, computer simulation, infiltration, multizone, residential buildings, and validation. 


\section{TABLE OF CONTENTS}

Abstract

iii

List of Tables

vii

List of Figures

$\begin{array}{ll}\text { Introduction } & 1\end{array}$

Experimental Method 2

\begin{tabular}{ll} 
Test House & 2 \\
\hline
\end{tabular}

Instrumentation $\quad 3$

$\begin{array}{ll}\text { Procedures } & 5\end{array}$

Simulation Method $\quad 6$

CONTAMW Model $\quad 6$

$\begin{array}{lr}\text { Statistical Evaluation of Model Predictions } & 9\end{array}$

$\begin{array}{ll}\text { Results } & 10\end{array}$

$\begin{array}{ll}\text { Air Change Rates } & 10\end{array}$

Comparison of Predicted and Measured Tracer Gas Concentrations 12

$\begin{array}{ll}\text { Summary } & 29\end{array}$

Attic Fan Case $\quad 31$

$\begin{array}{ll}\text { Discussion } & 33\end{array}$

$\begin{array}{ll}\text { Conclusion } & 35\end{array}$

$\begin{array}{ll}\text { Acknowledgements } & 36\end{array}$

$\begin{array}{ll}\text { References } & 37\end{array}$

Use of Non-SI Units in a NIST Publication

The policy of the National Institute of Standards and Technology is to use the International System of Units (metric units) in all its publications. However, in North America in the construction and heating, ventilation and air-conditioning (HVAC) industries, certain non-SI units are so widely used instead of SI units that it is more practical and less confusing to include measurement values for customary units only in the figures and tables of this report. 


\section{LiST OF TABLES}

1 HAC System Flows 4

2 Air Leakage Values $\quad 8$

3 Summary of $\mathrm{SF}_{6}$ Injection Test Cases 13

4 Statistical Parameters for Case \#1 - May 24, 2000

$5 \quad$ Statistical Parameters for Case \#2 - October 2, $2000 \quad 17$

$6 \quad$ Statistical Parameters for Case \#3 - March 9, 2001

$7 \quad$ Statistical Parameters for Case \#4 - January 19, 2001

$8 \quad$ Statistical Parameters for Case \#5 - March 16, 2001

9 Statistical Parameters for Case \#6 - July 24, 2000

10 Statistical Parameters for Case \#7 - February 16, 2001

11 Statistical Parameters for Case \#8 - March 30, 2001

12 Statistical Parameters for Case \#9 - June 22, 2001

13 Statistical Parameters for Case \#10 - February 27, 2001

14 Summary of Statistical Parameters 30

15 Statistical parameters for attic fan test case 32 


\section{LIST OF FigURES}

1 Front View of Townhouse 2

2 Schematic Floorplan of Townhouse 3

3 CONTAMW Sketchpad Representation of Townhouse 6

4 Measured and Simulated Blower Door Test Results 7

$5 \quad$ Measured and Predicted Townhouse Air Change Rates From Year 10

6 Regression of Overnight Air Change Rates vs. Absolute Indoor - Outdoor 11 Temperature Difference (January to December 2001)

7 Overnight Air Change Rates vs. Wind Speeds Measured at the Townhouse 12 (January to December 2001)

8 Predicted and Measured $\mathrm{SF}_{6}$ Concentrations for Case \#1 - May 24, $2000 \quad 14$

9 Average Infiltration by Zone for Case \#1 15

10 Predicted and Measured SF 6 Concentrations for Case \# 2 - October 2, $2000 \quad 16$

11 Predicted and Measured $\mathrm{SF}_{6}$ Concentrations for Case \# 3 - March 9, $2001 \quad 18$

12 Predicted and Measured SF6 Concentrations for Case \# 4 - January 19, 200119

13 Measured and Predicted Concentrations in the HAC Return for Case \# 4

14 Predicted and Measured $\mathrm{SF}_{6}$ Concentrations for Case \# 5 - March 16, 2001

15 Predicted and Measured SF 6 Concentrations for Case \# 6 - July 24, 2000

16 Measured and Predicted Concentrations in the HAC Return for Case \# 6

17 Predicted and Measured $\mathrm{SF}_{6}$ Concentrations for Case \# 7 - February 16, 200124

18 Measured and Predicted Concentrations in the HAC Return for Case \# 7

19 Predicted and Measured $\mathrm{SF}_{6}$ Concentrations for Case \# 8-March 30, 2001

20 Predicted and Measured $\mathrm{SF}_{6}$ Concentrations for Case \# 9 - June 22, 2001

21 Predicted and Measured $\mathrm{SF}_{6}$ Concentrations for Case \# 10 - February 27, 200128

22 Measured and Predicted Concentrations in the HAC Return for Case \# 10

23 Comparison of Predicted and Measured Zone Average Concentrations for All 31 Cases

24 Predicted (with and without attic fan) and measured $\mathrm{SF}_{6}$ conc. For attic fan case 32 


\section{INTRODUCTION}

There are two general types of computer simulation techniques for studying airflow and contaminant transport in buildings - zonal modeling and multizone modeling. Zonal (or room airflow) modeling takes a microscopic view by applying a computational fluid dynamics (CFD) program to examine the detailed flow fields and pollutant concentration distributions within a room or rooms. Multizone airflow and pollutant transport modeling takes a macroscopic view of indoor air quality by evaluating average pollutant concentrations in the different zones of a building as contaminants are transported through the building and its heating and air-conditioning (HAC) system. Each approach has strengths and limitations for studying different aspects of building ventilation and indoor air quality (IAQ).

The multizone approach is implemented by constructing a network of elements describing the flow paths (HAC ducts, doors, windows, cracks, etc.) between the zones of a building. The network nodes represent the zones, which are modeled at a uniform pressure, temperature, and pollutant concentration. After calculating the airflow between zones, including the ambient, zonal pollutant concentrations are calculated by applying mass balance equations to the zones, which may contain pollutant sources and/or sinks. Feustel and Dieris (1992) describes a survey of multizone airflow models. One multizone model is the CONTAM model developed in the Building and Fire Research Laboratory (BFRL) at the National Institute of Standards and Technology (NIST). The newest publicly available version of CONTAM is CONTAMW 2.0 (Dols et al. 2002).

Multizone IAQ modeling has been available as a research and analysis tool for over 20 years. However, due to improvements in such modeling programs (particularly the development of user friendly graphic interfaces), the availability of inexpensive computing power, and more complex building design requirements, the application of such programs has greatly increased and is moving from the research world to building designers, fire safety engineers, and other practitioners. This has, in turn, increased the need for establishing the validity of these models.

While a number of studies have examined the issue of validation as reviewed in Emmerich (2001), there is a need for further validation work - particularly in simulating the impact of IAQ control technologies (such as mechanical ventilation or improved air cleaners). This study builds on earlier work in which measurements and CONTAM predictions in a single-zone test house were compared (Emmerich and Nabinger 2001). This report describes experiments and simulations performed to evaluate the capability to accurately simulate tracer gas concentrations with a multizone airflow and indoor air quality (IAQ) model, in this case CONTAM. Measurements of tracer gas concentrations, building air change rates, and interzone airflow patterns were performed in a multizone townhouse. 


\section{EXPERIMENTAL Method}

\section{Test House}

The test house in this study is a three-story, four-bedroom, four-bathroom end-unit townhouse with a floor area of approximately $50 \mathrm{~m}^{2}$ per level (see Figures 1 and 2) and an overall volume of approximately $400 \mathrm{~m}^{3}$. The 30-year old townhouse is located in Reston, VA, approximately $35 \mathrm{~km}$ northwest of Washington, D.C. Tall trees on two sides (the property backs onto a $1.2 \times 10^{5} \mathrm{~m}^{2}$ forested park) and nearby townhouse rows shield the townhouse from wind. The townhouse is built on a slope such that there is a partial basement consisting of a utility room, pantry, bathroom, and recreation room with walkout patio. The middle level consists of a kitchen, dining room, living room, and bathroom. The top level contains four bedrooms and two bathrooms. Features of the house include sliding glass doors in the basement and living room, a furnace with no outdoor air intake, a fan that ventilates the attic with outdoor air when the attic temperature is elevated, a fireplace (flue always closed), exhaust fans in all four bathrooms, and a clothes dryer that exhausts to the outside. The townhouse's heating and air-conditioning (HAC) system uses $100 \%$ recirculated air and its ductwork does not enter the attic, resulting in no direct duct leakage to or from outside. Two blower door tests (ASTM E779) were performed (May 1999 and July 2000) to assess the envelope leakage of the house. The closed house air change rate at $50 \mathrm{~Pa}$ averaged $14.2 \mathrm{~h}^{-1}$ with an effective leakage area of $1120 \mathrm{~cm}^{2}$ at $4 \mathrm{~Pa}$. By opening the doors of the adjacent townhouse during the first test and seeing no significant change in pressure, it was determined there was negligible influence of the townhouse that shares a common wall.

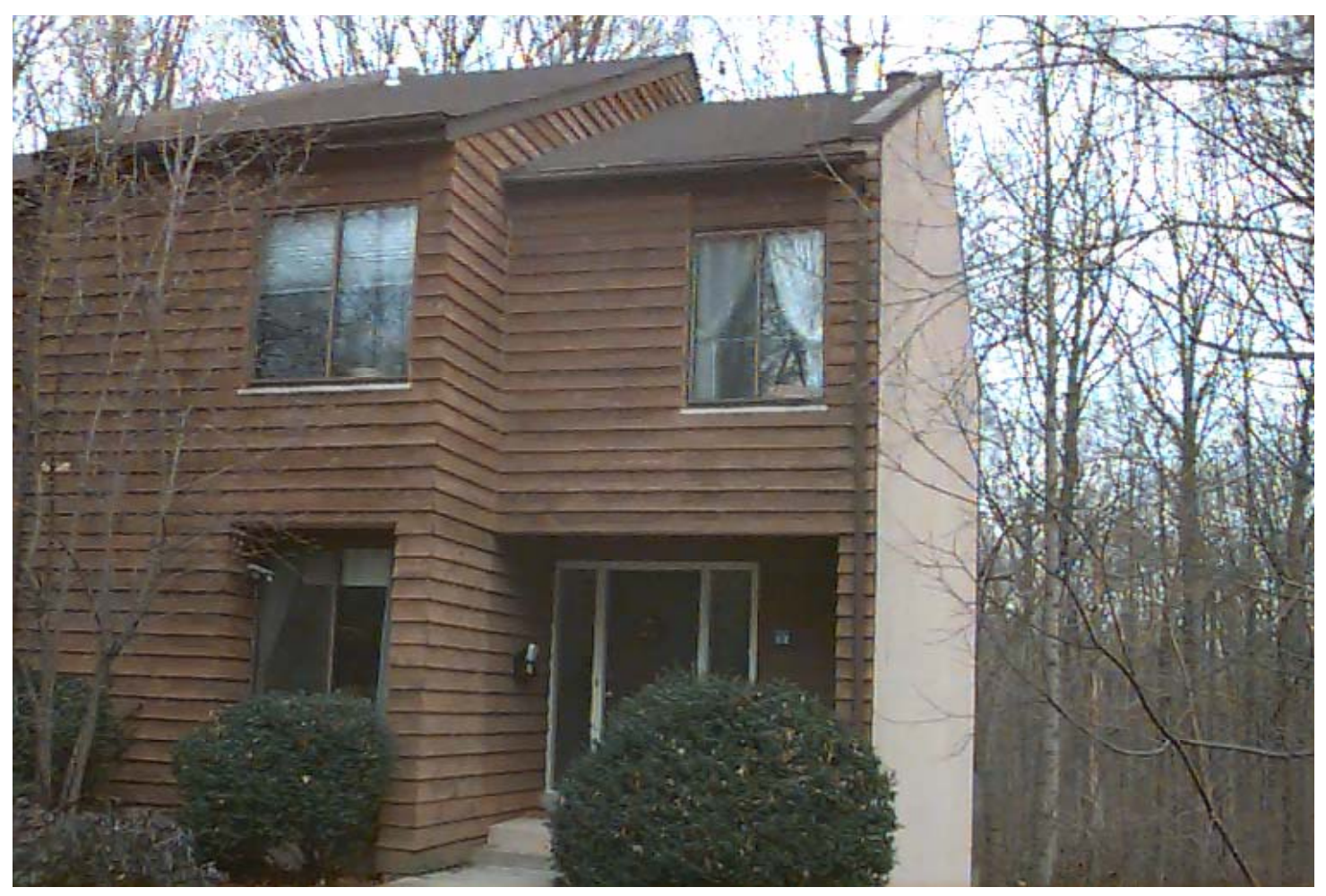

Figure 1 Front View of Townhouse 


\section{Instrumentation}

Building air change rates and interzone airflow patterns were assessed using an automated tracer gas measurement system consisting of a PC-based data acquisition and control system and a gas chromatograph (GC) with an electron capture detector (ECD). The GC-ECD was used to measure sulfur hexafluoride $\left(\mathrm{SF}_{6}\right)$ concentrations over a range of about $5 \mu \mathrm{g} / \mathrm{m}^{3}$ to $175 \mu \mathrm{g} / \mathrm{m}^{3}(1 \mathrm{ppb}(\mathrm{v})$ to $30 \mathrm{ppb}(\mathrm{v}))$ with an accuracy of approximately $2 \%$. The tracer gas system uses a ten-port sample valve to sample air at ten indoor locations every $10 \mathrm{~min}$. Thus, six measurements were taken in each location every hour.

Indoor and outdoor temperatures were measured with thermistors having an uncertainty of about $0.4{ }^{\circ} \mathrm{C}$. Wind speed and direction were measured using a sonic anemometer installed on the townhouse roof about $2 \mathrm{~m}(6.6 \mathrm{ft})$ above the crest of the roof. This is below the manufacturers recommendation of $10 \mathrm{~m}(33 \mathrm{ft})$ above the roof but was necessary due to constraints about appearance. Indoor and outdoor relative humidity was measured with bulk polymer resistance sensors with an accuracy of $3 \%$ of the reading.

First Floor

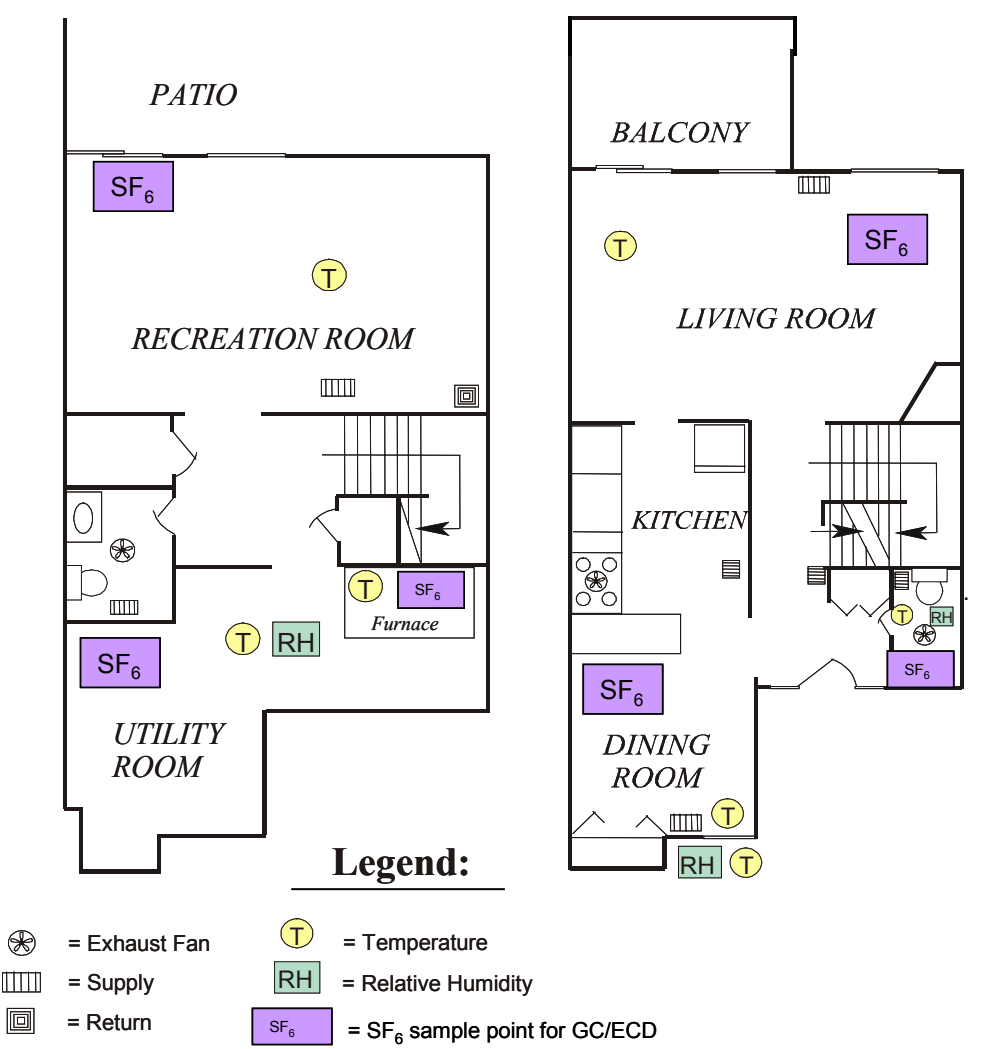

Third Floor

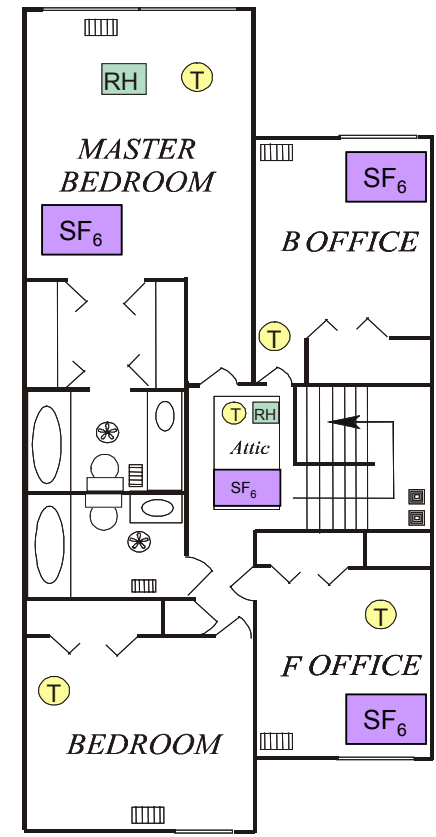

Figure 2 Schematic Floorplan of Townhouse

For most of the tests, there were ten indoor sampling locations for tracer gas and air temperature. The rooms included the utility and recreation rooms on the basement level, kitchen, bathroom and living room on the main level, master bedroom and two offices on 
the upstairs level, the attic, and the central return of the HAC system as seen in Figure 2. Most single point sample probes were located near the wall and many near the floor. Relative humidity was measured in one location on each level of the house. Early measurements found no $\mathrm{SF}_{6}$ in the outdoor air; the outdoor concentration of $\mathrm{SF}_{6}$ was assumed to be $0 \mu \mathrm{g} / \mathrm{m}^{3}$ for the remainder of the effort.

Table 1 HAC System Flows

\begin{tabular}{|l|c|c|c|}
\hline Supply location & Test 1 (L/s) & Test 2 (L/s) & Model (L/s) \\
\hline Front Office & 33 & 33.0 & 33 \\
\hline Second bedroom & 35 & 45 & 40 \\
\hline Bathroom, upstairs hall & $*$ & 24 & 24 \\
\hline Master Bedroom & 144 & 102 & 123 \\
\hline Master Bath & 43 & $*$ & 43 \\
\hline Back Office & 24 & 31 & 27 \\
\hline Living Room supply 1 & 38 & 50 & 44 \\
\hline Living Room supply2 & 31 & 12 & 21 \\
\hline Kitchen/Dining Room supply 1 & 12 & 59 & 35 \\
\hline Kitchen/Dining Room supply 2 & 31 & 52 & 41 \\
\hline 1st floor bath & $*$ & $*$ & 24 \\
\hline 1 st floor hallway & 21 & $*$ & 21 \\
\hline Basement Bathroom & 9.4 & 4.7 & 7 \\
\hline Rec supply 1 & 40 & 52 & 46 \\
\hline Rec supply 2 & $*$ & 28 & 28 \\
\hline Sum & 461 & 491 & 576 \\
\hline
\end{tabular}

* Supply either not measurable or missed during test. Total model supply flow includes a supply leak of $19 \mathrm{~L} / \mathrm{s}$ into the basement utility room.

The supply airflow rate through the HAC system was measured by performing a velocity traverse conducted in the supply air duct with a hot wire anemometer (HWA) to find a point representative of the average velocity in the return duct. A HWA was then mounted at that point to monitor duct airflow velocity during the experiments. The HWA has an uncertainty of $2.5 \%$ of the indicated reading. The measurements were performed in accordance with ASHRAE Standard 111 (ASHRAE 1988), which is estimated to result in an uncertainty of $5 \%$ to $10 \%$ under field conditions. The traverse test on the system supply was repeated several times and a similar traverse was performed on the system return to better characterize the system flows. The average supply flow was $530 \mathrm{~L} / \mathrm{s}$ and the average return flow was $675 \mathrm{~L} / \mathrm{s}$. While the HAC system was operating in fan constant mode, a balometer with an estimated accuracy of $10 \%$ was used to measure the individual HAC system supply flows with the results shown in Table 1. After accounting 
for not measurable flows the sum of measured supplies agreed reasonably well with the results of the traverse test. Attempts were made to measure the system return flows with the balometer also, however, accurate measurements were not possible due to the locations and magnitudes of those flows. A system duct leakage test confirmed the presence of significant supply and return leakage.

\section{Procedures}

Two types of tests were conducted in the townhouse, both using the tracer gas measurement system. The first type was used for measuring air change rates every four hours throughout the year. These tests involved automatic injections of $\mathrm{SF}_{6}$ with the HAC fan on continuously as opposed to being controlled by the system thermostat. Once injected, the $\mathrm{SF}_{6}$ decay rate was automatically calculated from the sampling point in the HAC system return for approximately $3.5 \mathrm{~h}$. This test was performed continuously throughout the year and was only interrupted by breakdowns, calibrations, or short-term tests (such as the manual injections described below).

The second type of test was measurements of $\mathrm{SF}_{6}$ transport from a single zone to the rest of the house for the purpose of comparison to CONTAMW model predictions (described later). These tests were performed by manually injecting $1500 \mathrm{~mL}$ of $1 \% \mathrm{SF}_{6}$ (in air) into a single room of the house. During the manual injections, the automatic injection system was turned off. Six cases were done with the HAC fan on. In order to also test the models mixing assumptions for the manual injections, no attempts to directly mix $\mathrm{SF}_{6}$ in the individual zones were made. 


\section{SiMULATION METHOD \\ CONTAMW Model}

This section of the report describes the CONTAMW model of the test house.

CONTAMW is a multizone airflow and pollutant transport model with a graphic interface used to create and edit a description of a building's features relating to airflow and the generation and removal of contaminants (Dols and Walton 2002). Multizone airflow and pollutant transport modeling takes a macroscopic view of air movement and IAQ by calculating average pollutant concentrations in the different zones of a building as contaminants are transported through the building and its HVAC system. The multizone approach is implemented by constructing a network of elements describing the flow paths (doors, windows, cracks, fan flows, etc.) between the zones of a building and between the building and ambient zone. The network nodes represent the zones that are modeled at a uniform pressure (varying with height), temperature, and pollutant concentration. After calculating the airflow between zones and ambient, zonal pollutant concentrations are calculated by applying mass balance equations to the zones, based on any modeled pollutant sources or sinks. The model uses ambient weather conditions and outdoor pollutant contaminant data to calculate these airflows and concentrations.

The graphical representations of the three main floors of the test house as they appear in CONTAMW are shown in Figure 3. The townhouse attic was included in the model as a single zone but is not shown. The layout of the townhouse within CONTAMW and the division of the zones (including those not labeled) were defined to represent the actual floorplan of the townhouse as seen in Figure 2, therefore each zone represents one room. The zones labeled in Figure 3 correspond to the zones in which the injections took place and/or locations of measured concentrations.

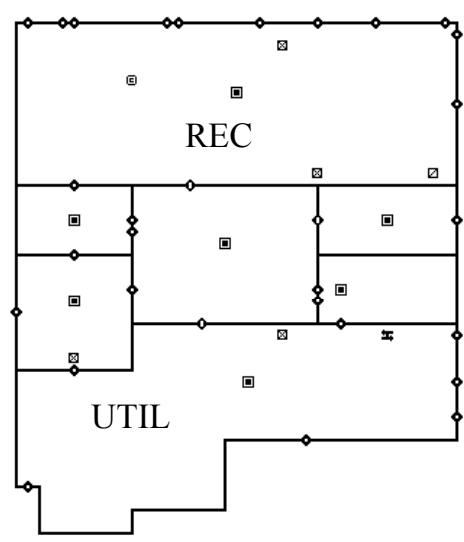

First Floor

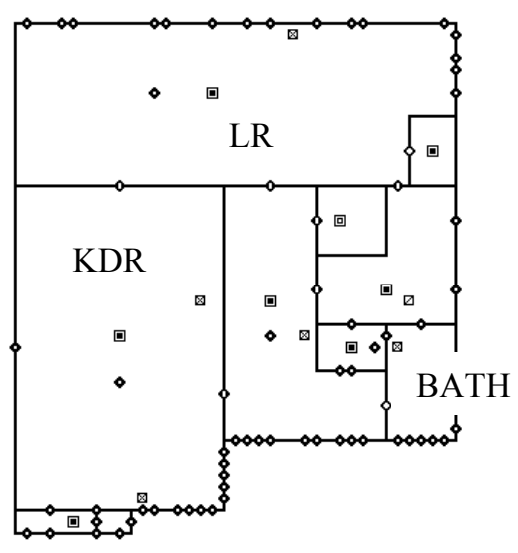

Second Floor

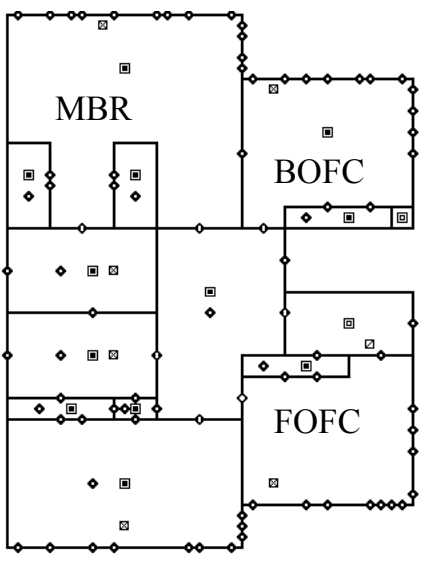

Third Floor

Figure 3 CONTAMW Sketchpad Representation of Townhouse (Note: The zone abbreviations correspond to the room descriptions given in Figure 2.) 
Ideally, the air leakage model of the house could be created by performing leakage tests on all individual airflow paths (wall joints, windows, etc.). However, due to the difficulty in isolating each individual path, this approach is impractical. An alternative approach was implemented where individual air leakage elements were first created in the CONTAMW model based on best estimate values from Table 25-3 of the ASHRAE Handbook of Fundamentals (ASHRAE 1997). This step ensures a more realistic distribution of appropriate airflow elements compared to uniform distribution of leakage on the exterior envelope. Then, the individual leakage elements were adjusted such that the resulting total flows from a simulated blower door test matched those from the measured blower door test. A comparison of the simulated and measured blower door test results is shown in Figure 4, and the resulting airflow leakage elements are summarized in Table 2. The leakage elements in Table 2 are based on a reference pressure difference of $4 \mathrm{~Pa}$ and a discharge of 1.0 with a flow exponent of 0.63 .

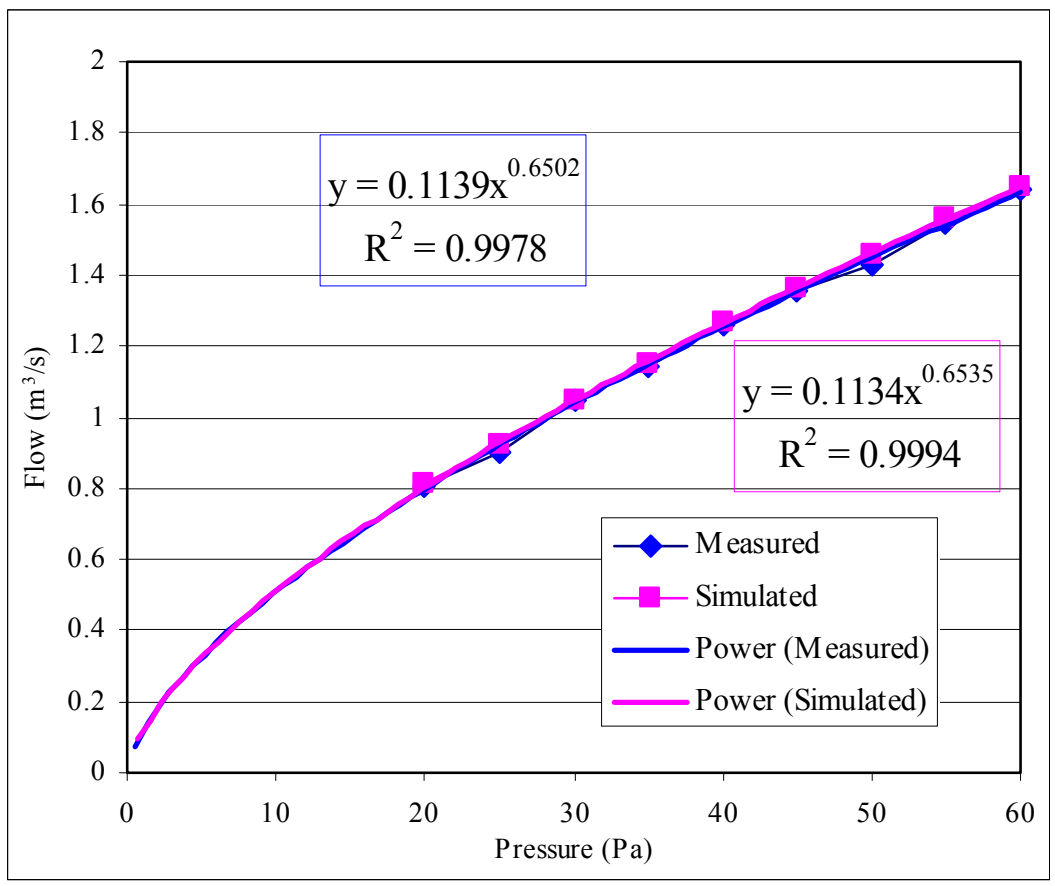

Figure 4 Measured and Simulated Blower Door Test Results 
Table 2 Air Leakage Values

\begin{tabular}{|l|c|}
\hline Airflow element description & $\begin{array}{c}\text { Effective Leakage Area } \\
\text { at } 4 \mathrm{~Pa}\end{array}$ \\
\hline Wall-wall joint & $1.5 \mathrm{~cm}^{2} / \mathrm{m}$ \\
\hline Ceiling-wall joint & $1.5 \mathrm{~cm}^{2} / \mathrm{m}$ \\
\hline Floor-wall joint & $4.0 \mathrm{~cm}^{2} / \mathrm{m}$ \\
\hline Window & $1.1 \mathrm{~cm}^{2} / \mathrm{m}$ \\
\hline Ceiling & $1.8 \mathrm{~cm}^{2} / \mathrm{m}^{2}$ \\
\hline Door/window frame & $1.7 \mathrm{~cm}^{2} / \mathrm{m}^{2}$ \\
\hline Front door & $21 \mathrm{~cm}^{2}$ \\
\hline Sliding glass door & $60 \mathrm{~cm}^{2}$ \\
\hline Wall penetrations & $6 \mathrm{~cm}^{2}$ \\
\hline Ceiling penetration & $6 \mathrm{~cm}^{2}$ \\
\hline Attic vents (17 total) & $0.00226 \mathrm{~m}^{2}$ \\
\hline Attic fan opening & $0.152 \mathrm{~m}^{2}$ \\
\hline Open interior doors (as two-way flow, one-opening elements) & Approx. measured size \\
\hline
\end{tabular}

To account for the effect of wind on a building, CONTAMW requires user inputs for a wind pressure modifier to account for local terrain effects and a wind pressure profile to account for relative wind direction (see Dols et al. 2000 for details on modeling wind effects in CONTAMW). Since the townhouse is almost surrounded by tall trees, the CONTAMW wind pressure modifiers for an urban location were used. This decision was supported by the observation that wind has a minimal impact on infiltration in the house (Wallace 2002). The wind pressure profile (i.e., wind pressure coefficients as a function of wind direction) was based on Figure 25.8 of the ASHRAE Handbook of Fundamentals (ASHRAE 1997).

The air handling system flows listed in Table 1 above were included in the house model using the CONTAMW simple air handling system model. The supply flows used in the house model were generally the average of the two measurements. In a few cases, the supply was not measured during a test. In these instances the one measured value was used. Since the flow for the $1^{\text {st }}$ floor bathroom could not be measured, the value for the $2^{\text {nd }}$ floor bathroom was substituted. Lacking accurate measurements for the return flows, the total modeled system supply flow of $580 \mathrm{~L} / \mathrm{s}$ was distributed equally between the three system returns. Since measurements could not accurately determine the locations or amounts of leakage, the only duct leakage included in the model was a $19 \mathrm{~L} / \mathrm{s}$ supply leak into the utility room representing leakage at the system itself.

Although this section summarizes the key model inputs, the complete CONTAMW project files are too large for inclusion here and will be made available on the NIST Multizone Modeling Website at www.bfrl.nist.gov/IAQanalysis. 


\section{Statistical Evaluation of Model Predictions}

The predicted tracer gas concentrations were compared with measured values using ASTM D5157 Standard Guide for Statistical Evaluation of Indoor Air Quality Models. This standard provides quantitative and qualitative tools for evaluation of IAQ models (ASTM 1997). It provides guidance in choosing data sets for model evaluation and focuses on evaluating the accuracy of indoor concentrations predicted by a model. As part of the comparison of CONTAMW predictions to measurements of tracer gas concentrations, the ASTM D5157 suggested criteria were applied. The data sets collected during this study meet the ASTM D5157 criteria for model evaluation, as they are entirely independent of the data used to develop the model and to estimate model inputs. Also, the data are of sufficient temporal and spatial detail to evaluate the CONTAMW predictions of individual zonal tracer gas concentrations.

ASTM D5157 provides three statistical tools for evaluating the accuracy of IAQ model predictions and two additional statistical tools for assessing bias. Values for these statistical criteria are provided to indicate whether the model performance is adequate. The tools for assessing agreement between predictions and measurements include:

1) The correlation coefficient of predictions and measurements should be 0.9 or greater.

2) The line of regression between the predictions and measurements should have a slope between 0.75 and 1.25 and an intercept less than $25 \%$ of the average measured concentration.

3) The normalized mean square error (NMSE) should be less than 0.25 . The NMSE is calculated as:

$$
N M S E=\sum_{i=1}^{N}\left(C_{p i}-C_{o i}\right)^{2} / 2 \bar{C}_{o} \bar{C}_{p}
$$

where $\mathrm{C}_{\mathrm{p}}$ is the predicted concentration and $\mathrm{C}_{\mathrm{o}}$ is the observed concentration, and the over-bar represents an average over the $\mathrm{N}$ data points during the test period for each test case.

ASTM D5157 also provides two statistical measures of bias with values for judging adequate model performance. These measures of bias include:

1) Normalized fractional bias (FB) of the mean concentrations. Fractional bias should be 0.25 or smaller and is calculated as:

$$
F B=2\left(\bar{C}_{p}-\bar{C}_{o}\right) /\left(\bar{C}_{p}+\bar{C}_{o}\right)
$$

2) Fractional bias based on the variance (FS) which should be 0.5 or smaller. FS is calculated as:

$$
F S=2\left({\sigma_{p}}^{2}-\sigma_{o}{ }^{2}\right) /\left(\sigma_{p}{ }^{2}+\sigma_{o}{ }^{2}\right)
$$

where $\sigma_{\mathrm{p}}$ is the standard deviation of the predicted concentrations and $\sigma_{\mathrm{o}}$ is the standard deviation of the observed concentrations. 


\section{RESULTS}

\section{Air Change Rates}

The townhouse air change rate was measured using the tracer gas decay method (ASTM 2000) using the automated $\mathrm{SF}_{6}$ injection system previously described. Measurements were taken beginning approximately $25 \mathrm{~min}$ after the tracer gas release and ending prior to the next injection approximately $3 \mathrm{~h}$ and $30 \mathrm{~min}$ later. Figure 5 shows air change rates vs. indoor - outdoor temperature differences for most 4-hour periods from the year 2001 . Also shown on Figure 5 are air change rates predicted by the CONTAMW model of the townhouse for wind speeds of $0 \mathrm{~m} / \mathrm{s}$ and $6 \mathrm{~m} / \mathrm{s}$ for the average of the four wind directions. The measured 4-hour average wind speed was nearly always less than $4 \mathrm{~m} / \mathrm{s}$ and typically ranged from $1 \mathrm{~m} / \mathrm{s}$ to $3 \mathrm{~m} / \mathrm{s}$. No formal comparison was made between these measured and predicted values as there was no attempt to control occupant activity at all times (i.e., window opening, fan operation, etc.). However, given this lack of control the predicted air change rates appear reasonably close to the measured values with the main discrepancy being over-prediction of air change rates at large temperature differences.

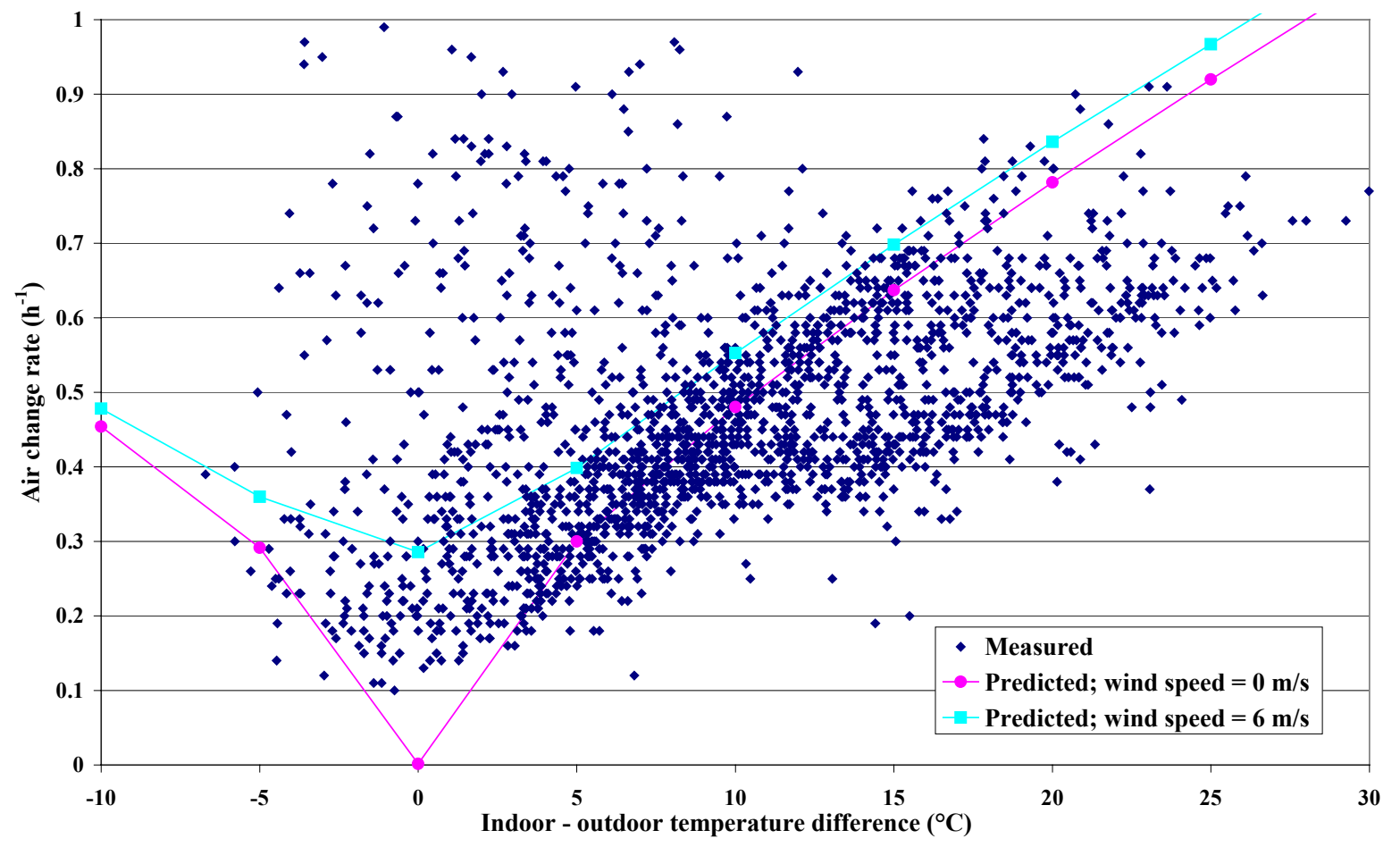

Figure 5 Measured and predicted townhouse air change rates

Figure 6 shows a regression of the overnight air change rates against the absolute value of the indoor - outdoor temperature differences that allows comparison to an earlier study of air change rates in the same townhouse (see Figure 8 of Wallace et al. 2002). Figure 6 is limited to overnight periods to minimize the potential for window opening or other occupant impacts on the air change rates. Compared to the Wallace's et.al. earlier work, Figure 5 shows a larger slope ( 0.019 compared to 0.016$)$ and intercept ( 0.24 compared to 0.18 ) with a lower correlation coefficient ( 0.76 compared to 0.91$)$. Given the broader 
seasonal range of Figure 6 and the inevitable operating variability of an occupied house, these two studies agree well.

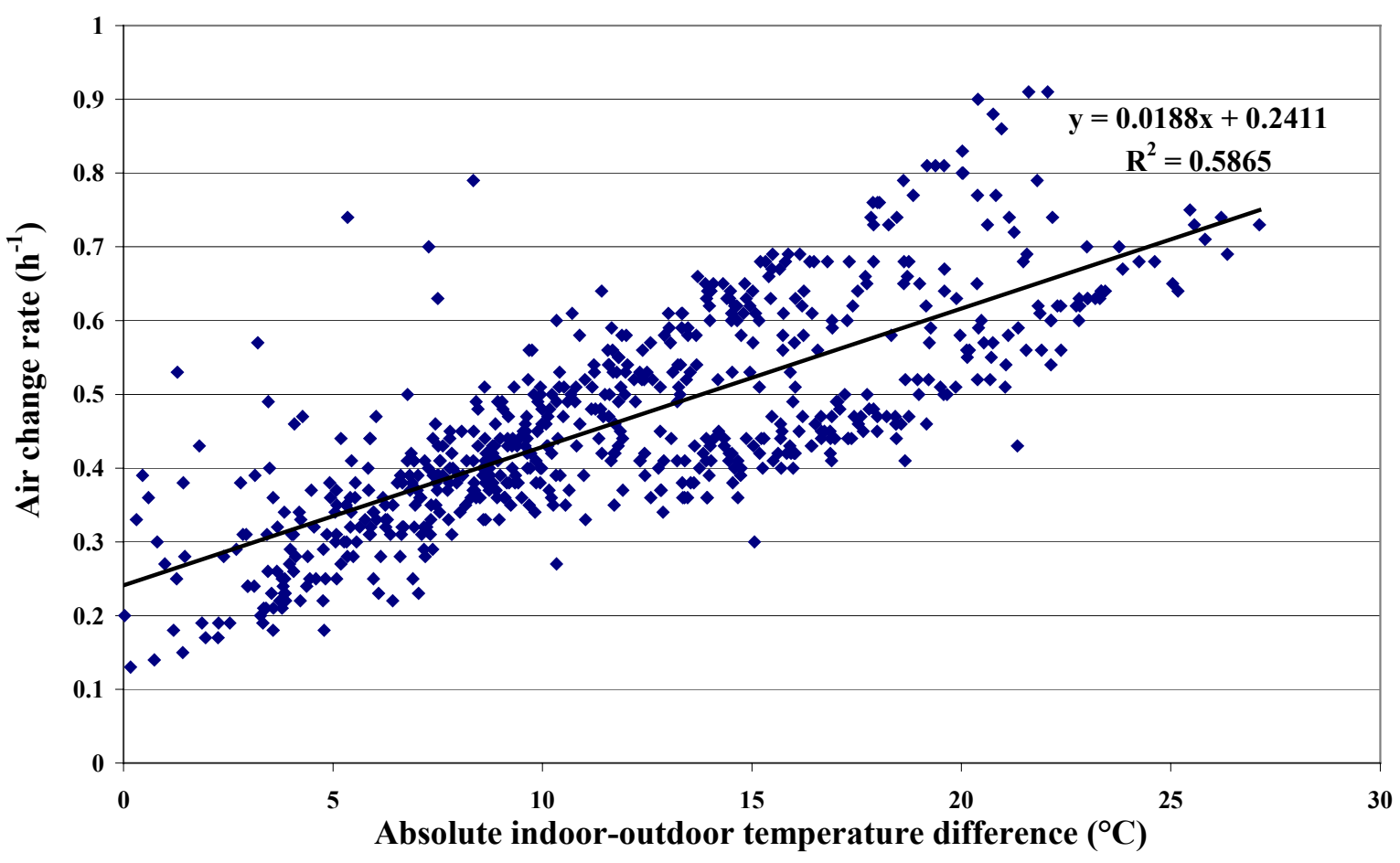

Figure 6 Regression of overnight air change rate vs. absolute indoor-outdoor temperature difference (January to December 2001)

The 2001 overnight air change data also confirm Wallace's report of little to no impact of measured wind conditions on air change rates in the townhouse (Wallace et al. 2002). Figure 7 shows the measured overnight air change rate vs. average measured wind speed for those time periods with an indoor-outdoor temperature difference of less than $10{ }^{\circ} \mathrm{C}$. For comparison, the figure also shows the predicted air change rate over the same range of wind speeds for indoor - outdoor temperature differences from $0{ }^{\circ} \mathrm{C}$ to $10{ }^{\circ} \mathrm{C}$. While the data show no obvious trend, the predictions bracket the majority of the measurements. The few measured values significantly above the predictions may have been occasions when windows were left open at night. The minimal effect of wind is likely due to the townhouse's location in a heavily wooded area that surrounds two of the three exposed walls. 


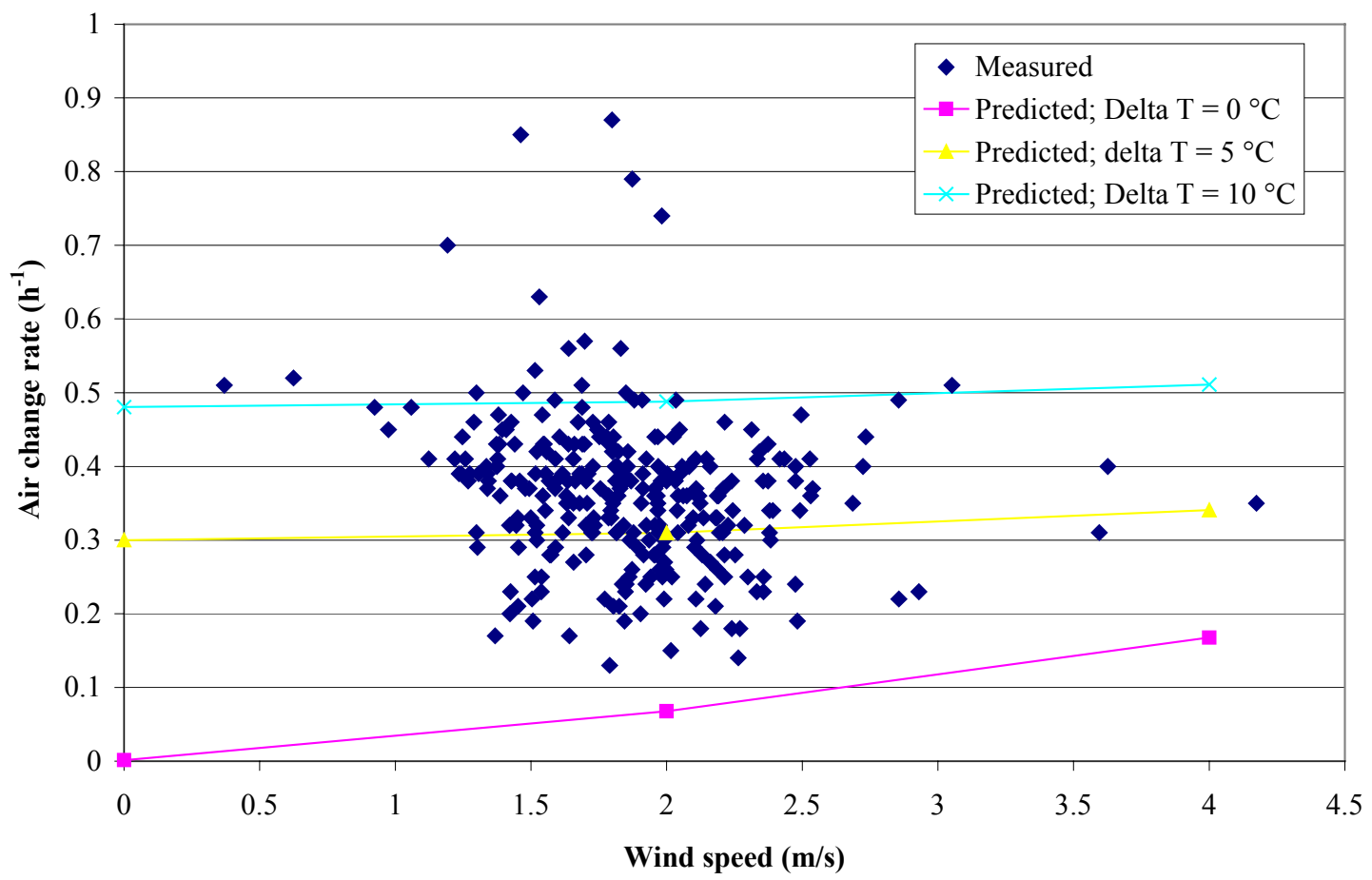

Figure 7 Overnight air change rates vs. wind speeds (January to December 2001)

Comparison of Predicted and Measured Tracer Gas Concentrations

A total of ten experiments were conducted and simulations performed under a variety of conditions for test dates between May 2000 and June 2001 for the purpose of comparing predicted and measured tracer gas concentrations. The tests consisted of injecting tracer gas $\left(1 \% \mathrm{SF}_{6}\right)$ and measuring the concentrations for $2 \mathrm{~h}$ to $6 \mathrm{~h}$. The test cases are summarized in Table 3 including the date, injection zone, HAC fan status, average indoor and outdoor temperature, and average wind speed. The HAC system was on in four cases. The zones in which injections took place included the recreation room (REC) on the $1^{\text {st }}$ floor, the kitchen/dining room (KDR) on the $2^{\text {nd }}$ floor, and the master bedroom (MBR) on the $3^{\text {rd }}$ floor. 
Table 3 Summary of $\mathrm{SF}_{6}$ injection test cases

\begin{tabular}{|c|c|c|c|c|c|c|}
\hline Case & Test Date & $\begin{array}{c}\text { Injection } \\
\text { Zone }\end{array}$ & HAC Fan & $\begin{array}{c}\text { Avg } \\
\mathbf{T}_{\text {in }}\left({ }^{\circ} \mathbf{C}\right)\end{array}$ & $\begin{array}{c}\text { Avg } \\
\mathbf{T}_{\text {out }}\left({ }^{\circ} \mathbf{C}\right)\end{array}$ & $\begin{array}{c}\text { Avg } \\
\mathbf{V}_{\text {wind }}(\mathbf{m} / \mathbf{s})\end{array}$ \\
\hline 1 & May 24, 2000 & KDR & Off & 26.4 & 29.4 & 3.6 \\
\hline 2 & Oct. 2, 2000 & KDR & Off & 24.5 & 24.4 & 1.3 \\
\hline 3 & March 9, 2001 & KDR & Off & 18.8 & 9.3 & 1.7 \\
\hline 4 & January 19, 2001 & KDR & On & 22.4 & 5.2 & 0.4 \\
\hline 5 & March 16, 2001 & REC & Off & 20.6 & 10.6 & 1.0 \\
\hline 6 & July 24, 2000 & REC & On & 26.2 & 19.5 & 2.6 \\
\hline 7 & Feb. 16, 2001 & REC & On & 18.6 & 6.7 & 2.4 \\
\hline 8 & March 30, 2001 & MBR & Off & 21.4 & 14.5 & 2.3 \\
\hline 9 & June 22, 2001 & MBR & Off & 26.9 & 26.3 & 1.2 \\
\hline 10 & Feb. 27, 2001 & MBR & On & 20.6 & 21.6 & 2.5 \\
\hline
\end{tabular}

\section{Case \#1}

The first test case was an injection in the KDR zone with the HAC system off. The measured and predicted $\mathrm{SF}_{6}$ concentrations for the individual zones are shown in Figure 8. Table 4 shows average and standard deviation of both the observed and predicted concentrations along with the ASTM D5157 statistical parameters (described previously) calculated for both the individual zones - REC, KDR, MBR, utility room (UTIL), living room (LR), back office (BOFC), front office (FOFC), main floor bathroom (BATH), and attic (ATC) - and for the overall zone average. The suggested ASTM D5157 statistical criteria were evaluated for both individual zone transient concentrations and overall zone average concentrations for the entire testing period for all cases. The columns of Table 4 (and subsequent tables) include the zone, average observed concentration $\left(\mathrm{C}_{\mathrm{o}}\right)$ in $\mathrm{ppb}(\mathrm{v})$, average predicted concentration $\left(\mathrm{C}_{\mathrm{p}}\right)$ in $\mathrm{ppb}(\mathrm{v})$, standard deviation of observed concentrations $\left(\sigma_{\mathrm{o}}\right)$, standard deviation of predicted concentrations $\left(\sigma_{\mathrm{p}}\right)$, correlation coefficient $(\mathrm{R})$, regression slope $(\mathrm{m})$, regression intercept divided by the average observed concentration $\left(\mathrm{b} / \mathrm{C}_{\mathrm{o}}\right)$, normalized mean square error (NMSE), fractional bias of the mean concentrations (FB), and fractional bias based on the variance (FS). The average concentration in the bottom row of the tables is a linear average of the nine zone concentrations in $\mathrm{ppb}(\mathrm{v})$. 

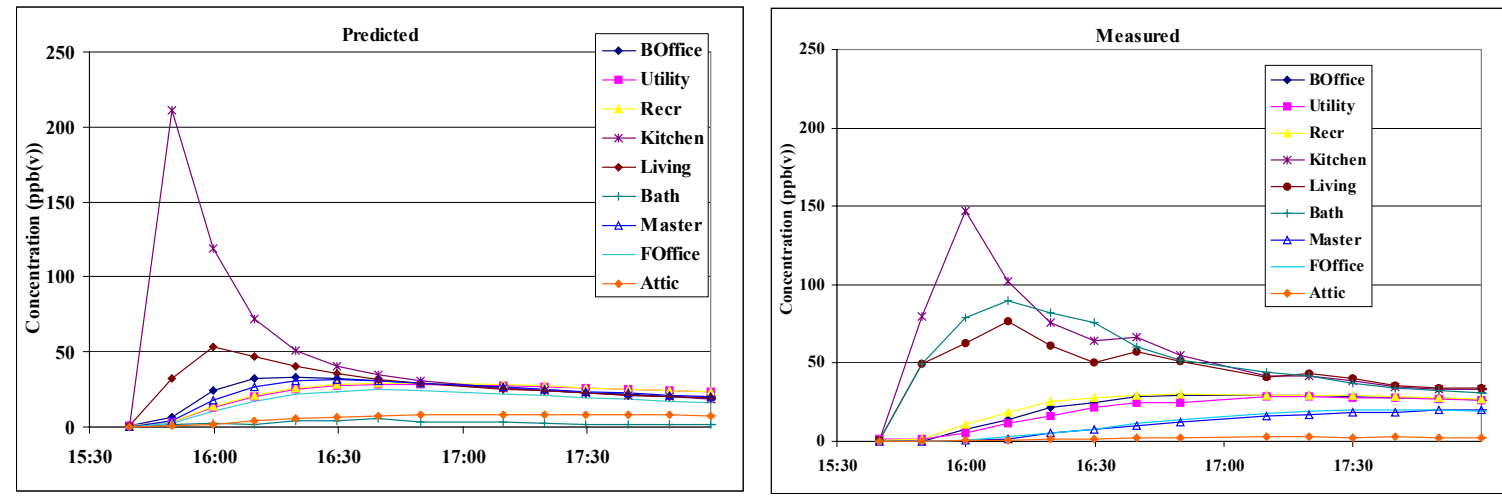

Figure 8 Predicted and measured $\mathrm{SF}_{6}$ concentrations for Case \#1

Table 4 Statistical parameters for Case \#1 (concentrations in ppb(v))

\begin{tabular}{|l|c|c|c|c|c|c|c|c|c|c|}
\hline Zone & $\mathbf{C}_{\mathbf{0}}$ & $\mathbf{C}_{\mathbf{p}}$ & $\boldsymbol{\sigma}_{\mathbf{0}}$ & $\boldsymbol{\sigma}_{\mathbf{p}}$ & $\mathbf{R}$ & $\mathbf{m}$ & $\mathbf{b} / \mathbf{C}_{\mathbf{0}}(\mathbf{\%})$ & $\mathbf{N M S E}$ & $\mathbf{F B}$ & $\mathbf{F S}$ \\
\hline REC & 22.9 & 21.9 & 10 & 8.9 & $\mathbf{0 . 9 7}$ & $\mathbf{0 . 8 5}$ & $\mathbf{1 0}$ & $\mathbf{0 . 0 1}$ & $\mathbf{- 0 . 0 5}$ & $\mathbf{- 0 . 2 7}$ \\
\hline UTIL & 20.0 & 21.4 & 10 & 8.7 & $\mathbf{0 . 9 0}$ & $\mathbf{0 . 7 7}$ & 30 & $\mathbf{0 . 0 5}$ & $\mathbf{0 . 0 7}$ & $\mathbf{- 0 . 2 9}$ \\
\hline LR & 44.5 & 28.0 & 18 & 13 & $\mathbf{0 . 9 4}$ & 0.69 & $\mathbf{- 6 . 2}$ & $\mathbf{0 . 2 5}$ & -0.45 & -0.60 \\
\hline KDR (inj. zone) & 56.3 & 47.3 & 35 & 53 & 0.67 & $\mathbf{1 . 0}$ & $\mathbf{- 1 7}$ & 0.58 & $\mathbf{- 0 . 1 7}$ & 0.78 \\
\hline MBR & 11.3 & 21.8 & 8.1 & 9.1 & 0.35 & 0.40 & 150 & 0.81 & 0.64 & $\mathbf{0 . 2 3}$ \\
\hline BOFC & 21.5 & 22.8 & 10 & 9.3 & 0.62 & 0.55 & 51 & $\mathbf{0 . 1 5}$ & $\mathbf{0 . 0 6}$ & $\mathbf{- 0 . 2 5}$ \\
\hline FOFC & 12.0 & 17.0 & 8.2 & 7.5 & 0.56 & 0.51 & 90 & 0.37 & 0.34 & $\mathbf{- 0 . 1 8}$ \\
\hline BATH & 49.3 & 2.5 & 24 & 1.3 & 0.63 & 0.03 & $\mathbf{1 . 7}$ & 22 & -1.8 & -2.0 \\
\hline ATC & 1.8 & 6.0 & 1.0 & 3.0 & $\mathbf{0 . 9 6}$ & 2.7 & 56 & 1.9 & 1.0 & 1.5 \\
\hline $\begin{array}{l}\text { Average } \\
\text { Concentrations }\end{array}$ & 26.6 & 21.0 & 19 & 13 & 0.46 & 0.31 & 48 & 0.54 & $\mathbf{- 0 . 2 4}$ & -0.73 \\
\hline
\end{tabular}

The bold values in the table are those that met the ASTM suggested criteria. Based on most of the statistical parameters, this case resulted in the poorest agreement of all the cases between measurements and predictions. Specifically, the values for $\mathrm{R}, \mathrm{m}, \mathrm{b} / \mathrm{Co}$, NMSE, and FS calculated for the comparison of average zone concentrations all fall outside the ASTM D5157 suggested limits with most of them being worse than for any other test case. However, much of the discrepancy is due to a single zone, the BATH, which is discussed later as being a particularly difficult zone in the simulations.

Excluding the BATH zone from consideration increases R to 0.93 for the average concentrations and also brings all the other statistical parameters very close to the ASTM suggested limits. The MBR zone also suffered from poor agreement as the model overpredicted the amount of $\mathrm{SF}_{6}$ that would reach this zone on the third floor. On average, the model under-predicts the zone average concentrations by about $20 \%$ and, as Figure 8 shows, predicts mixing throughout the house to occur more quickly than measured. 
Several conditions likely contributed to Case \# 1 having the poorest agreement between measured and predicted values. These conditions included the HAC system being off, the outdoor temperature being the highest of any case with an average of $29.4^{\circ} \mathrm{C}$, and the average wind speed being the highest of any case at $3.6 \mathrm{~m} / \mathrm{s}$. Although wind speed had minimal impact on the air change rate in the townhouse as discussed above, it has been noted in other validation studies that high wind speed conditions commonly presents a challenge to multizone airflow models. This may be because the detailed leakage distribution may have a larger effect on the flow patterns that depend on wind direction (Emmerich 2001). For example, Bassett (1990) found that calculated airflows were more sensitive to wind direction than measured airflows. In this case, the wind direction played an important role as the primarily southwest wind during the simulation helped pressurize the bath zone and prevented tracer gas from entering that room. Test simulations with reduced wind speed or different wind directions showed far more $\mathrm{SF}_{6}$ entering the BATH zone, although not nearly as much as measured.

Two other factors likely contributed to the severe under-prediction of $\mathrm{SF}_{6}$ concentration in the BATH. First, the BATH zone is likely a bit too leaky in the model. Figure 9 below shows that the infiltration directly to the BATH is far higher than any other zone. Although the BATH zone has more outside wall area (relative to zone volume) than any other zone and thus may be expected to have somewhat higher infiltration, the difference seems larger than it should be. However, no measurements were made to characterize the leakiness of individual zones. Finally, the airflow element connecting the BATH zone to the adjacent hallway in the model is a two-way airflow element that estimates mixing between the zones based on the temperature difference between the zones. For this case, the average temperature difference between the zones is only $0.3{ }^{\circ} \mathrm{C}$, reducing the extent of air and tracer gas transport in and out of the BATH zone relative to what measurements indicate actually occurred.

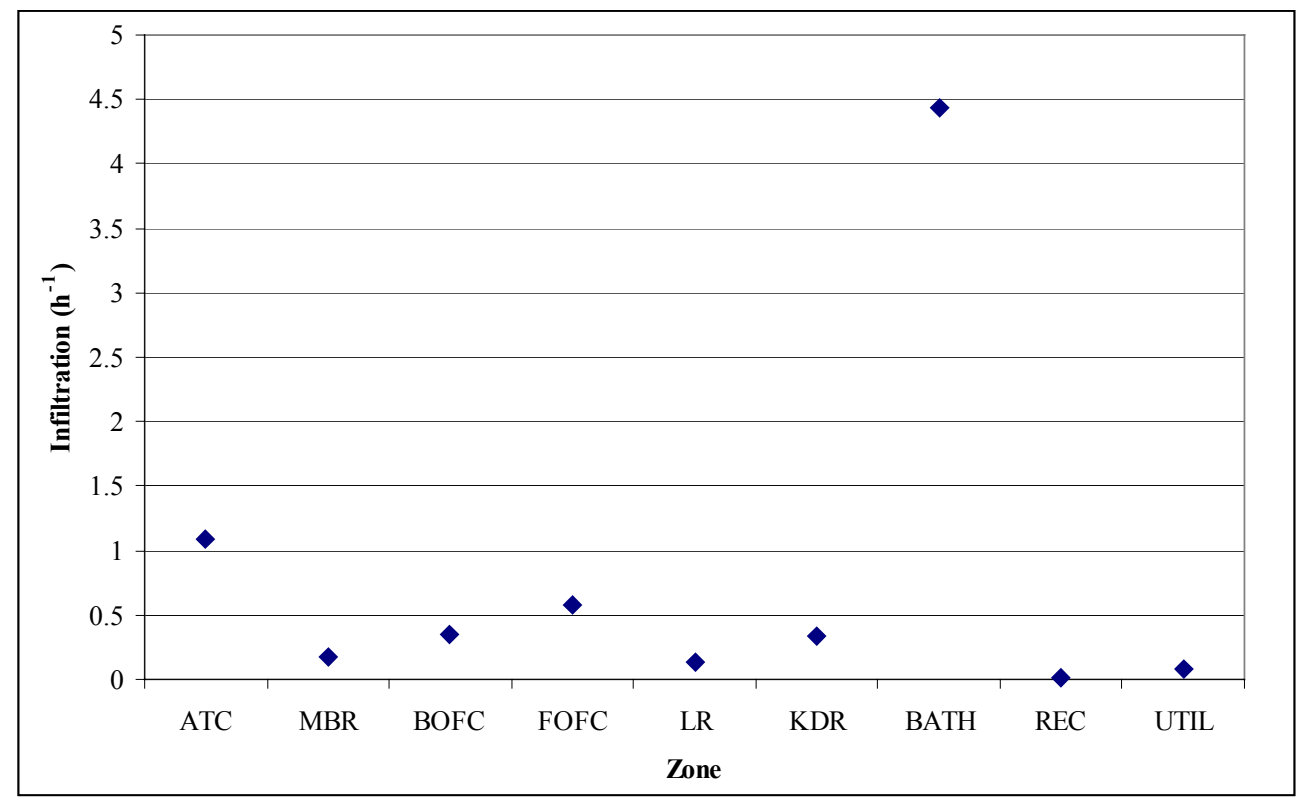

Figure 9 Average infiltration by zone for Case \#1 
Case \# 2

As with Case \# 1, Case \# 2 involved an injection in the KDR zone with the HAC system fan off. The individual zones' measured and predicted concentrations are shown in Figure 10 and the calculated D5157 statistical parameters are shown in Table 5. The outdoor temperature was warm at $24.4{ }^{\circ} \mathrm{C}$ but several degrees cooler than Case \# 1 , and the average wind speed was much lower at $1.3 \mathrm{~m} / \mathrm{s}$. Overall, the agreement between measurements and predictions was much better with the comparison for the average concentrations meeting or coming close to most of the ASTM D5157 suggested limits. The correlation coefficient and the slope were a bit low at 0.81 and 0.57 respectively. Most of the predicted zone concentrations agreed very well with the measurements, with only the BATH and ATC zones exhibiting poor agreement. The BATH prediction was significantly lower than the measurement but the agreement was much better than the first case. With the BATH zone excluded, the overall correlation coefficient improves to 0.9 . The main discrepancy between measured and predicted concentrations was caused by an overall predicted average concentration that was about $20 \%$ below the average measured concentration, which is only partially due to the large under-prediction in the BATH zone.

Also, despite the injection occurring in the KDR zone, the measured peak concentration in the LR zone was higher than in the KDR zone. This result is not too surprising as the measurement locations for the two zones (near the east wall of the LR and the west wall of the KDR) were nearly the same distance from the injection location in the middle of the kitchen space of the KDR zone.
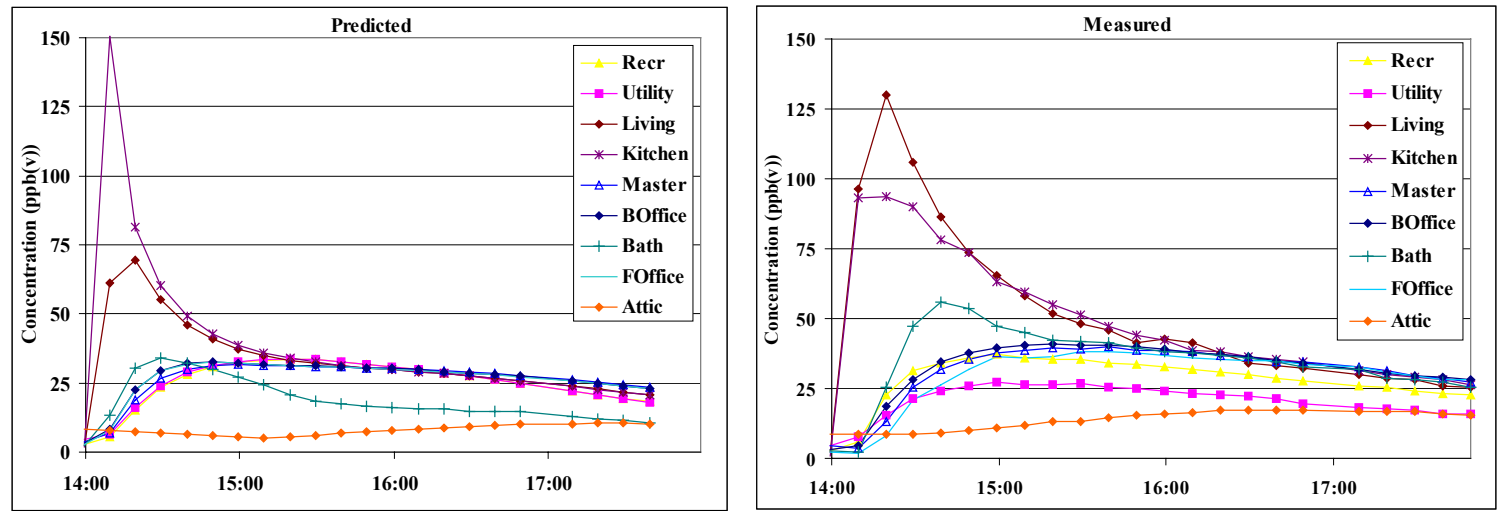

Figure 10 Predicted and measured $\mathrm{SF}_{6}$ concentrations for Case \# 2 
Table 5 Statistical parameters for Case \# 2 (concentrations in ppb(v))

\begin{tabular}{|l|c|c|c|c|c|c|c|c|c|c|}
\hline Zone & $\mathbf{C}_{\mathbf{0}}$ & $\mathbf{C}_{\mathbf{p}}$ & $\boldsymbol{\sigma}_{\mathbf{0}}$ & $\boldsymbol{\sigma}_{\mathbf{p}}$ & $\mathbf{R}$ & $\mathbf{m}$ & $\mathbf{b} / \mathbf{C}_{\mathbf{0}}(\mathbf{\%})$ & $\mathbf{N M S E}$ & $\mathbf{F B}$ & $\mathbf{F S}$ \\
\hline REC & 28.2 & 24.7 & 8.8 & 8.7 & $\mathbf{0 . 9 7}$ & $\mathbf{0 . 9 5}$ & $-\mathbf{7 . 7}$ & $\mathbf{0 . 0 2}$ & $\mathbf{- 0 . 1 3}$ & $\mathbf{- 0 . 0 3}$ \\
\hline UTIL & 20.6 & 25.0 & 5.9 & 8.4 & $\mathbf{0 . 9 9}$ & 1.4 & $\mathbf{- 1 9}$ & $\mathbf{0 . 0 5}$ & $\mathbf{0 . 1 9}$ & 0.66 \\
\hline LR & 50.6 & 32.6 & 30 & 14 & $\mathbf{0 . 9 8}$ & 0.47 & $\mathbf{1 7}$ & 0.33 & -0.43 & -1.2 \\
\hline KDR (inj. zone) & 48.7 & 37.6 & 24 & 29 & 0.81 & $\mathbf{0 . 9 8}$ & $\mathbf{- 2 1}$ & $\mathbf{0 . 2 1}$ & $\mathbf{- 0 . 2 6}$ & $\mathbf{0 . 3 9}$ \\
\hline MBR & 31.2 & 26.1 & 10 & 7.3 & $\mathbf{0 . 9 6}$ & 0.67 & $\mathbf{1 7}$ & $\mathbf{0 . 0 5}$ & $\mathbf{- 0 . 1 7}$ & -0.69 \\
\hline BOFC & 32.1 & 26.5 & 10 & 7.4 & $\mathbf{0 . 9 5}$ & 0.67 & $\mathbf{1 5}$ & $\mathbf{0 . 0 5}$ & $\mathbf{- 0 . 1 9}$ & -0.67 \\
\hline FOFC & 29.4 & 26.4 & 11 & 7.4 & 0.85 & 0.58 & 32 & $\mathbf{0 . 0 5}$ & $\mathbf{- 0 . 1 1}$ & -0.73 \\
\hline BATH & 34.8 & 18.0 & 13 & 7.8 & 0.73 & 0.43 & $\mathbf{8 . 2}$ & 0.56 & -0.64 & -0.96 \\
\hline ATC & 13.9 & 8.0 & 3.4 & 1.8 & 0.64 & 0.34 & $\mathbf{2 4}$ & 0.34 & -0.52 & -1.1 \\
\hline $\begin{array}{l}\text { Average } \\
\text { Concentrations }\end{array}$ & 32.2 & 25.0 & 12 & 8.4 & 0.81 & 0.57 & $\mathbf{2 0}$ & $\mathbf{0 . 1 2}$ & $\mathbf{- 0 . 2 5}$ & -0.67 \\
\hline
\end{tabular}

Case \# 3

As with the previous 2 cases, the third test involved an injection in the Kitchen with the HAC system off. The individual zones' measured and predicted transient concentrations are shown in Figure 11, and the D5157 statistical parameters are shown in Table 6. The ambient conditions were quite different from Cases 1 and 2, with the average outdoor temperature only $9.3{ }^{\circ} \mathrm{C}$ and the average wind speed of $1.7 \mathrm{~m} / \mathrm{s}$. The comparison between measurements and simulations fell between the two cases with the agreement being better than the first case but worse than the second case. Once again, the biggest difference between the predictions and measurements was in the BATH, with substantially lower predicted concentration than measured. As before, the comparison of average concentrations improves greatly $(\mathrm{R}=0.93)$ with the BATH zone excluded. Also, transient predictions for most zones compare very well to the measurements with the ASTM criteria being met for many zones. The overall average concentration is under-predicted by $13 \%$, in this case due entirely to the under-prediction in the BATH. 

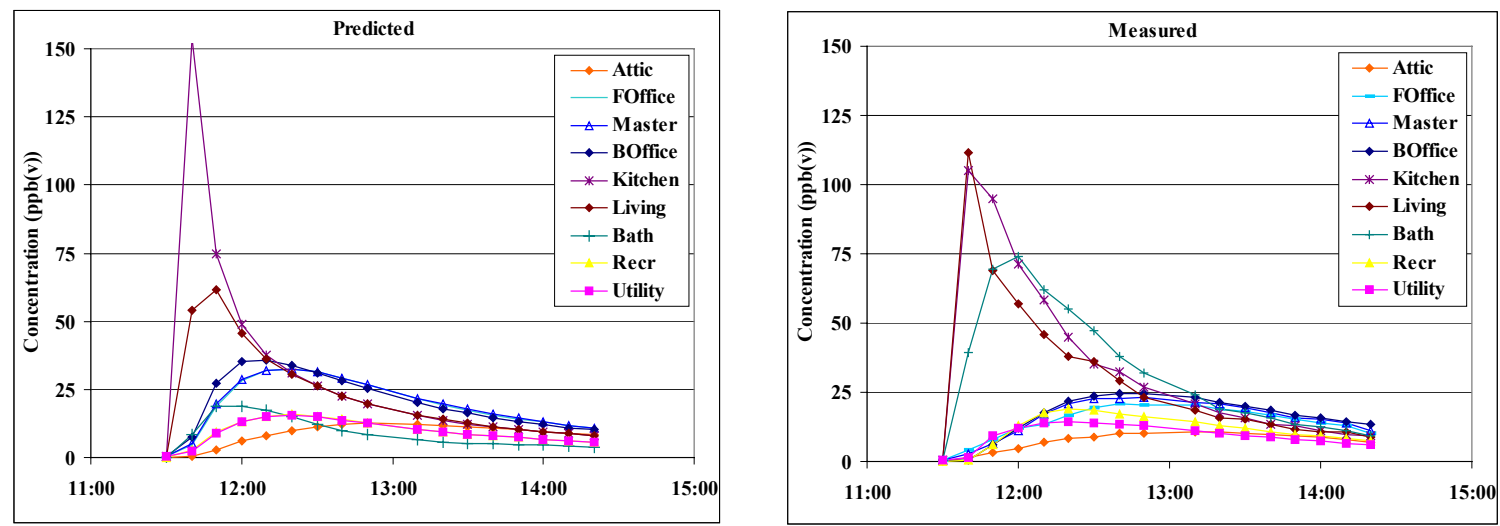

Figure 11 Predicted and measured $\mathrm{SF}_{6}$ concentrations for Case \#3

Table 6 Statistical parameters for Case \# 3 (concentrations in ppb(v))

\begin{tabular}{|l|c|c|c|c|c|c|c|c|c|c|}
\hline Zone & $\mathbf{C}_{\mathbf{0}}$ & $\mathbf{C}_{\mathbf{p}}$ & $\sigma_{\mathbf{0}}$ & $\sigma_{\mathbf{p}}$ & $\mathbf{R}$ & $\mathbf{m}$ & $\mathbf{b} / \mathbf{C}_{\mathbf{0}}(\mathbf{\%})$ & $\mathbf{N M S E}$ & $\mathbf{F B}$ & $\mathbf{F S}$ \\
\hline REC & 11.3 & 9.5 & 5.7 & 4.5 & $\mathbf{0 . 9 4}$ & $\mathbf{0 . 7 4}$ & $\mathbf{9 . 4}$ & $\mathbf{0 . 0 7}$ & $\mathbf{- 0 . 1 8}$ & $\mathbf{- 0 . 4 7}$ \\
\hline UTIL & 9.3 & 9.4 & 4.1 & 4.3 & $\mathbf{0 . 9 8}$ & $\mathbf{1 . 0}$ & $\mathbf{- 4 . 0}$ & $\mathbf{0 . 0 0 6}$ & $\mathbf{0 . 0 0 3}$ & $\mathbf{0 . 1 1}$ \\
\hline LR & 30.2 & 22.8 & 28 & 17 & $\mathbf{0 . 9 3}$ & 0.58 & $\mathbf{1 7}$ & 0.33 & -0.28 & -0.88 \\
\hline KDR (inj. zone) & 34.1 & 29.6 & 31 & 37 & $\mathbf{0 . 9 1}$ & $\mathbf{1 . 1}$ & $\mathbf{- 2 1}$ & $\mathbf{0 . 2 4}$ & $\mathbf{- 0 . 1 4}$ & $\mathbf{0 . 3 3}$ \\
\hline MBR & 15.4 & 19.5 & 7.0 & 9.7 & 0.72 & $\mathbf{0 . 9 9}$ & 27 & $\mathbf{0 . 2 0}$ & $\mathbf{0 . 2 3}$ & 0.62 \\
\hline BOFC & 16.1 & 20.0 & 7.7 & 11 & 0.52 & 0.72 & 53 & 0.30 & $\mathbf{0 . 2 2}$ & 0.62 \\
\hline FOFC & 14.2 & 19.3 & 5.9 & 9.7 & 0.70 & $\mathbf{1 . 2}$ & $\mathbf{2 0}$ & $\mathbf{0 . 2 6}$ & 0.30 & 0.92 \\
\hline BATH & 31.8 & 8.7 & 23 & 5.7 & $\mathbf{0 . 9 9}$ & 0.25 & $\mathbf{2 . 8}$ & 2.9 & -1.1 & -1.8 \\
\hline ATC & 7.5 & 8.7 & 3.3 & 4.0 & $\mathbf{0 . 9 9}$ & $\mathbf{1 . 2}$ & $\mathbf{- 3 . 6}$ & $\mathbf{0 . 0 3}$ & $\mathbf{0 . 1 5}$ & 0.37 \\
\hline $\begin{array}{l}\text { Average } \\
\text { Concentrations }\end{array}$ & 18.9 & 16.4 & 10 & 7.6 & 0.56 & 0.41 & 45 & $\mathbf{0 . 2 4}$ & $\mathbf{- 0 . 1 4}$ & $\mathbf{- 0 . 5 2}$ \\
\hline
\end{tabular}

Case \# 4

Case \# 4 also involved an injection in the KDR zone but with the HAC fan on. In this case, and in others, when the HAC system was on, the KDR zone was excluded from statistical analysis because the measuring point in this zone was located directly above the supply vent. With the system operating, the measured value was not indicative of zone concentrations and therefore excluded. The ambient conditions were cold (average $\mathrm{T}_{\text {out }}$ of $5.2^{\circ} \mathrm{C}$ ) and calm (average wind speed of $0.4 \mathrm{~m} / \mathrm{s}$ ). As seen in Figure 12, the HAC system operation results in significant mixing between zones within one hour after the injection. As shown in Table 7, the agreement between measurements and predictions is very good for both individual zone transient concentrations and zone average concentrations, with nearly all parameters meeting the D5157 criteria. 

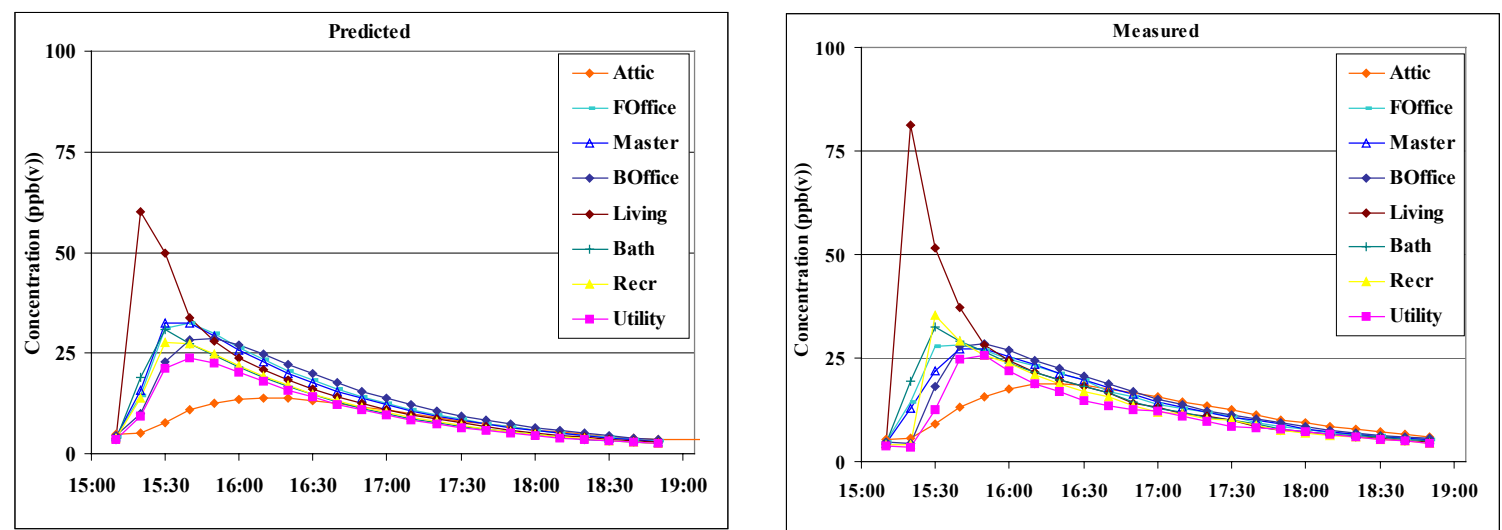

Figure 12 Predicted and measured $\mathrm{SF}_{6}$ concentrations for Case \# 4

Table 7 Statistical parameters for Case \# 4 (concentrations in ppb(v))

\begin{tabular}{|l|c|c|c|c|c|c|c|c|c|c|}
\hline Zone & $\mathbf{C}_{\mathbf{0}}$ & $\mathbf{C}_{\mathbf{p}}$ & $\sigma_{\mathbf{0}}$ & $\sigma_{\mathbf{p}}$ & $\mathbf{R}$ & $\mathbf{m}$ & $\mathbf{b} / \mathbf{C}_{\mathbf{0}}(\mathbf{\%})$ & $\mathbf{N M S E}$ & $\mathbf{F B}$ & $\mathbf{F S}$ \\
\hline REC & 13.1 & 11.4 & 8.8 & 8.1 & $\mathbf{0 . 9 5}$ & $\mathbf{0 . 8 7}$ & $\mathbf{- 0 . 2}$ & $\mathbf{0 . 0 7}$ & $\mathbf{- 0 . 1 4}$ & $\mathbf{- 0 . 1 6}$ \\
\hline UTIL & 11.3 & 10.2 & 6.5 & 7.0 & $\mathbf{0 . 9 2}$ & $\mathbf{0 . 9 7}$ & $-\mathbf{7 . 1}$ & $\mathbf{0 . 0 7}$ & $\mathbf{- 0 . 1 0}$ & $\mathbf{0 . 1 2}$ \\
\hline LR & 17.9 & 15.4 & 18 & 15 & $\mathbf{0 . 9 8}$ & $\mathbf{0 . 8 3}$ & $\mathbf{3 . 2}$ & $\mathbf{0 . 0 8}$ & $\mathbf{- 0 . 1 5}$ & $\mathbf{- 0 . 3 4}$ \\
\hline KDR (inj. zone) & 13.8 & 18.2 & $*$ & $*$ & $*$ & $*$ & $*$ & $*$ & $*$ & $*$ \\
\hline MBR & 14.2 & 13.4 & 7.5 & 9.6 & $\mathbf{0 . 9 6}$ & $\mathbf{1 . 2}$ & -28 & $\mathbf{0 . 0 6}$ & $\mathbf{- 0 . 0 5}$ & $\mathbf{0 . 4 9}$ \\
\hline BOFC & 14.2 & 13.5 & 8.0 & 8.6 & $\mathbf{0 . 9 7}$ & $\mathbf{1 . 0}$ & $\mathbf{- 9 . 3}$ & $\mathbf{0 . 0 2}$ & $\mathbf{- 0 . 0 4}$ & $\mathbf{0 . 1 5}$ \\
\hline FOFC & 14.3 & 13.6 & 7.8 & 9.5 & $\mathbf{0 . 9 9}$ & $\mathbf{1 . 2 1}$ & $\mathbf{- 2 5}$ & $\mathbf{0 . 0 2}$ & $\mathbf{- 0 . 0 5}$ & $\mathbf{0 . 3 8}$ \\
\hline BATH & 14.1 & 11.6 & 8.4 & 8.5 & $\mathbf{1 . 0}$ & $\mathbf{1 . 0}$ & $\mathbf{- 1 9}$ & $\mathbf{0 . 0 4}$ & $\mathbf{- 0 . 1 9}$ & $\mathbf{0 . 0 4}$ \\
\hline ATC & 12.1 & 8.6 & 4.6 & 3.6 & $\mathbf{0 . 9 7}$ & $\mathbf{0 . 7 6}$ & $\mathbf{- 4 . 7}$ & $\mathbf{0 . 1 3}$ & $\mathbf{- 0 . 3 3}$ & $\mathbf{- 0 . 4 8}$ \\
\hline $\begin{array}{l}\text { Average } \\
\text { Concentrations }\end{array}$ & 13.9 & 12.2 & 2.0 & 2.2 & $\mathbf{0 . 8 8}$ & $\mathbf{0 . 9 6}$ & $\mathbf{- 8 . 2}$ & $\mathbf{0 . 0 1 8}$ & $\mathbf{- 0 . 1 3}$ & $\mathbf{0 . 1 9}$ \\
\hline
\end{tabular}

*KDR zone excluded from statistical analysis

For all cases with the HAC system operating, the predicted and measured concentrations in the central return duct were compared as a surrogate indicator of overall agreement for whole house average concentrations. As shown in Figure 13, there is very good agreement between the measured and predicted concentrations in the central return duct of the HAC system for case 4 with all parameters meeting the D5157 criteria. The overall average concentration is under predicted by about $10 \%$. 


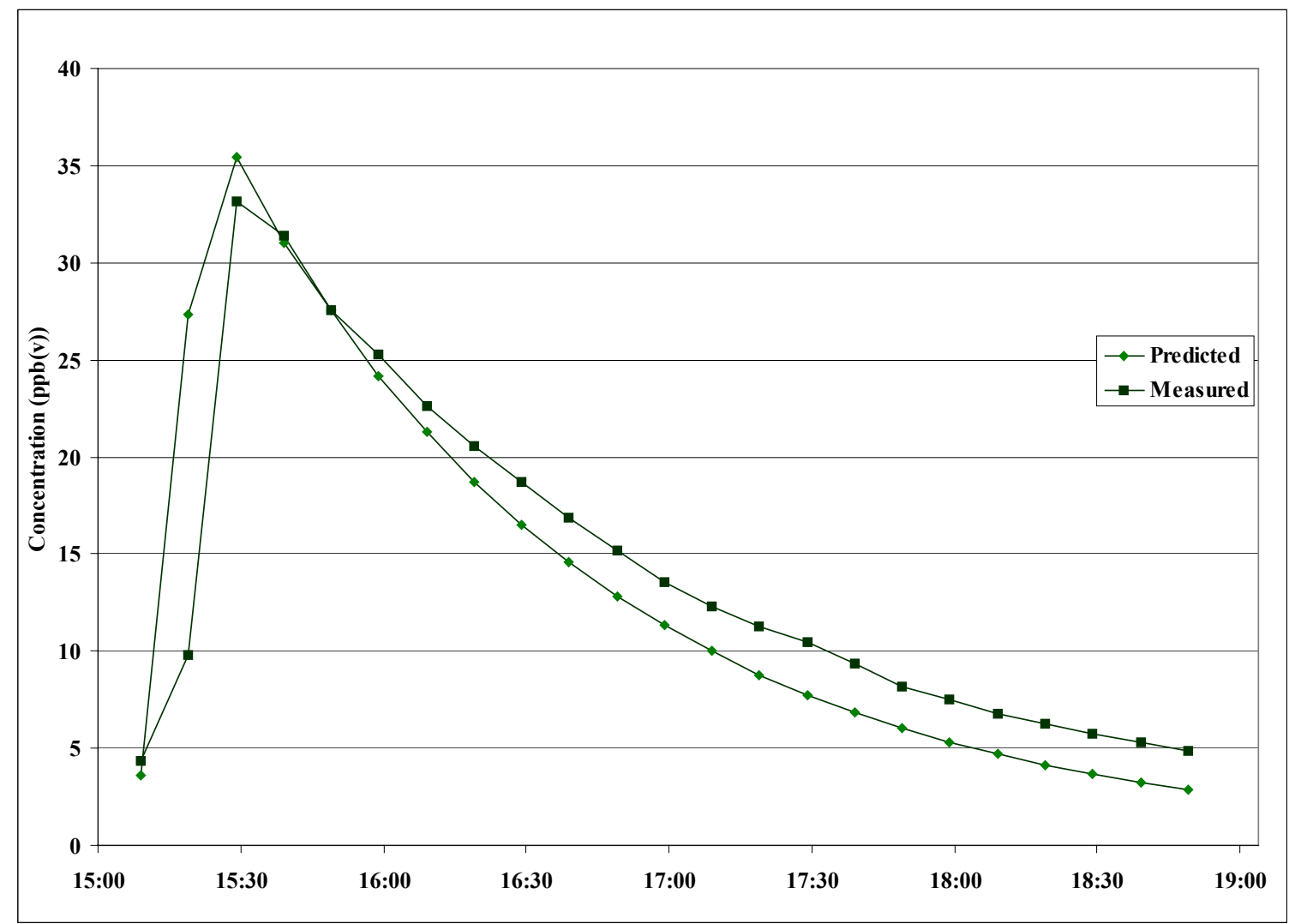

Figure 13 Measured and predicted concentrations in the HAC return for Case \# 4

Case \# 5

The test for Case \# 5 involved an injection in the basement REC zone with the HAC system off. The ambient conditions were cold $\left(10.6^{\circ} \mathrm{C}\right)$ and calm $(1.0 \mathrm{~m} / \mathrm{s})$. The zones' measured and predicted transient concentrations, shown in Figure 14, compared reasonably well, with the BATH zone again showing the poorest comparison. The D5157 statistical parameters are presented in Table 8. Although the BATH zone concentration was under predicted, the difference was less for this case compared to the KDR injection cases. The model also over-predicted the concentration in the UTIL zone on the same floor as the injection zone. The correlation coefficient between zone average concentrations was fair at 0.75 and the overall average predicted concentration was within $10 \%$ of the measured. 

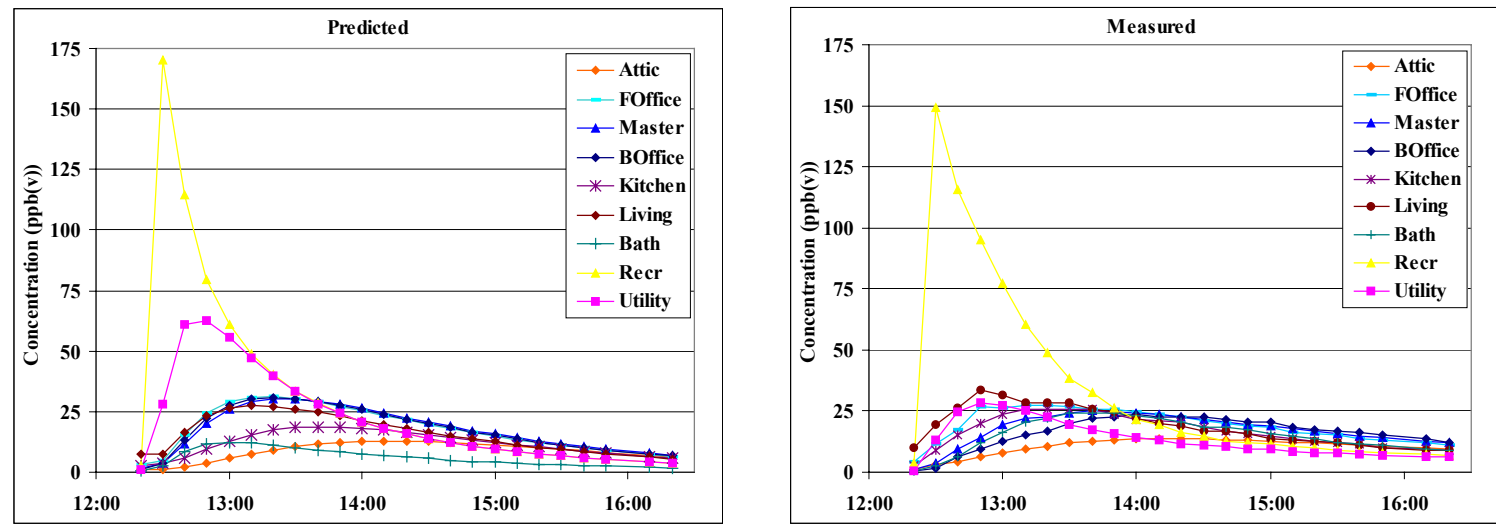

Figure 14 Predicted and measured $\mathrm{SF}_{6}$ concentrations for Case \# 5

Table 8 Statistical parameters for Case \# 5 (concentrations in ppb(v))

\begin{tabular}{|l|c|c|c|c|c|c|c|c|c|c|}
\hline Zone & $\mathbf{C}_{\mathbf{0}}$ & $\mathbf{C}_{\mathbf{p}}$ & $\sigma_{\mathbf{0}}$ & $\sigma_{\mathbf{p}}$ & $\mathbf{R}$ & $\mathbf{m}$ & $\mathbf{b} / \mathbf{C}_{\mathbf{0}}(\mathbf{\%})$ & $\mathbf{N M S E}$ & $\mathbf{F B}$ & $\mathbf{F S}$ \\
\hline REC (inj. zone) & 31.1 & 30.5 & 40 & 40 & $\mathbf{1 . 0}$ & $\mathbf{0 . 9 9}$ & $\mathbf{- 0 . 7}$ & $\mathbf{0 . 0 0 1}$ & $\mathbf{- 0 . 0 2}$ & $\mathbf{- 0 . 0 2}$ \\
\hline UTIL & 13.5 & 21.8 & 7.6 & 18.9 & $\mathbf{0 . 9 8}$ & 2.4 & -81 & 0.67 & 0.47 & 1.44 \\
\hline LR & 19.0 & 16.0 & 7.8 & 7.5 & $\mathbf{0 . 9 1}$ & $\mathbf{0 . 8 8}$ & $\mathbf{- 4 . 2}$ & $\mathbf{0 . 0 6}$ & $\mathbf{- 0 . 1 7}$ & $\mathbf{- 0 . 0 6}$ \\
\hline KDR & 16.8 & 12.1 & 6.6 & 5.0 & $\mathbf{0 . 8 8}$ & 0.67 & $\mathbf{4 . 8}$ & $\mathbf{0 . 1 6}$ & $\mathbf{- 0 . 3 3}$ & $\mathbf{- 0 . 5 3}$ \\
\hline MBR & 17.6 & 17.8 & 6.4 & 8.9 & $\mathbf{0 . 9 0}$ & $\mathbf{1 . 2}$ & $\mathbf{- 2 3}$ & $\mathbf{0 . 0 5}$ & $\mathbf{0 . 0 2}$ & 0.63 \\
\hline BOFC & 16.3 & 17.9 & 6.6 & 9.1 & 0.59 & $\mathbf{0 . 8 1}$ & 28 & $\mathbf{0 . 1 9}$ & $\mathbf{0 . 0 9}$ & 0.63 \\
\hline FOFC & 19.4 & 18.1 & 6.4 & 9.0 & $\mathbf{0 . 9 8}$ & 1.4 & -43 & $\mathbf{0 . 0 3}$ & $\mathbf{- 0 . 0 7}$ & 0.65 \\
\hline BATH & 15.5 & 6.0 & 6.9 & 3.6 & 0.61 & 0.32 & $\mathbf{6 . 8}$ & 1.2 & -0.87 & -1.1 \\
\hline ATC & 10.4 & 8.8 & 3.5 & 3.7 & $\mathbf{0 . 9 8}$ & $\mathbf{1 . 0}$ & $\mathbf{- 1 9}$ & $\mathbf{0 . 0 3}$ & $\mathbf{- 0 . 1 7}$ & $\mathbf{0 . 1 0}$ \\
\hline $\begin{array}{l}\text { Average } \\
\text { Concentrations }\end{array}$ & 17.7 & 16.6 & 5.7 & 7.2 & 0.75 & $\mathbf{0 . 9 5}$ & $\mathbf{- 1 . 5}$ & $\mathbf{0 . 0 7}$ & $\mathbf{- 0 . 0 7}$ & $\mathbf{0 . 4 6}$ \\
\hline
\end{tabular}

Case \# 6

Case \# 6 involved an injection in the REC room with the central HAC system on during warm ambient conditions $\left(19.5^{\circ} \mathrm{C}\right)$. The measured and predicted transient zone concentrations are shown in Figure 15. As with Case \# 4 with the HAC system operating, the agreement between measurements and predictions was excellent for both individual zone transient predictions and for zone average predictions. Nearly every parameter met the D5157 criteria (see Table 9). 

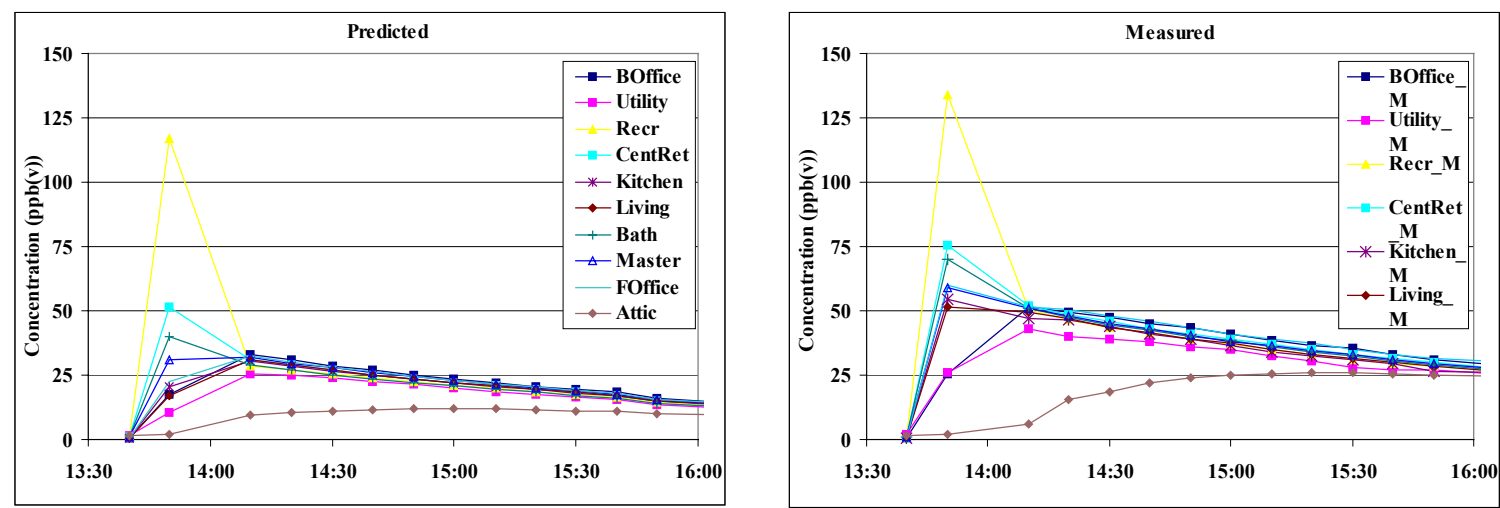

Figure 15 Predicted and measured $\mathrm{SF}_{6}$ concentrations for Case \# 6

Table 9 Statistical parameters for Case \# 6 (concentrations in ppb(v))

\begin{tabular}{|l|c|c|c|c|c|c|c|c|c|c|}
\hline Zone & $\mathbf{C}_{\mathbf{0}}$ & $\mathbf{C}_{\mathbf{p}}$ & $\boldsymbol{\sigma}_{\mathbf{0}}$ & $\boldsymbol{\sigma}_{\mathbf{p}}$ & $\mathbf{R}$ & $\mathbf{m}$ & $\mathbf{b} / \mathbf{C}_{\mathbf{0}}(\mathbf{\%})$ & $\mathbf{N M S E}$ & $\mathbf{F B}$ & $\mathbf{F S}$ \\
\hline REC (inj. zone) & 20.0 & 21.0 & 13 & 23 & $\mathbf{0 . 9 8}$ & 1.7 & -64 & $\mathbf{0 . 2 4}$ & $\mathbf{0 . 0 4}$ & 0.99 \\
\hline UTIL & 16.0 & 14.9 & 5.7 & 6.4 & $\mathbf{0 . 9 7}$ & $\mathbf{1 . 1}$ & $\mathbf{- 1 8}$ & $\mathbf{0 . 0 2}$ & $\mathbf{- 0 . 0 7}$ & $\mathbf{0 . 2 6}$ \\
\hline LR & 18.1 & 17.0 & 7.0 & 7.5 & $\mathbf{0 . 9 2}$ & $\mathbf{0 . 9 8}$ & $\mathbf{- 4 . 0}$ & $\mathbf{0 . 0 3}$ & $\mathbf{- 0 . 0 6}$ & $\mathbf{0 . 1 3}$ \\
\hline KDR & 17.8 & 17.0 & $*$ & $*$ & $*$ & $*$ & $*$ & $*$ & $*$ & $*$ \\
\hline MBR & 18.9 & 18.2 & 7.4 & 8.2 & $\mathbf{0 . 9 8}$ & $\mathbf{1 . 1}$ & $\mathbf{- 1 3}$ & $\mathbf{0 . 0 1}$ & $\mathbf{- 0 . 0 4}$ & $\mathbf{0 . 2 2}$ \\
\hline BOFC & 18.9 & 18.0 & 6.9 & 8.0 & $\mathbf{0 . 9 8}$ & $\mathbf{1 . 1}$ & $\mathbf{- 1 8}$ & $\mathbf{0 . 0 1}$ & $\mathbf{- 0 . 0 5}$ & $\mathbf{0 . 3 0}$ \\
\hline FOFC & 20.0 & 18.0 & 7.6 & 7.9 & $\mathbf{0 . 9 4}$ & $\mathbf{0 . 9 8}$ & $\mathbf{- 7 . 7}$ & $\mathbf{0 . 0 3}$ & $\mathbf{- 0 . 1 0}$ & $\mathbf{0 . 0 9}$ \\
\hline BATH & 19.0 & 17.0 & 8.0 & 8.7 & $\mathbf{0 . 9 9}$ & $\mathbf{1 . 1}$ & $\mathbf{- 1 8}$ & $\mathbf{0 . 0 2}$ & $\mathbf{- 0 . 1 1}$ & $\mathbf{0 . 1 6}$ \\
\hline ATC & 12.0 & 9.2 & 4.4 & 2.8 & 0.80 & 0.51 & $\mathbf{2 5}$ & $\mathbf{0 . 1 4}$ & -0.27 & -0.84 \\
\hline $\begin{array}{l}\text { Average } \\
\text { Concentrations }\end{array}$ & 17.9 & 16.7 & 2.5 & 3.2 & $\mathbf{0 . 9 6}$ & $\mathbf{1 . 2}$ & -32 & $\mathbf{0 . 0 1}$ & $\mathbf{- 0 . 0 7}$ & 0.51 \\
\hline
\end{tabular}

*KDR zone excluded from statistical analysis

As with Figure 13 for Case \# 4, Figure 16 shows the measured and predicted concentrations in the central return of the HAC system for case \# 6. The agreement is excellent with $\mathrm{R}=0.98$ and the remaining parameters also meeting the $\mathrm{D} 5157$ criteria. The overall average predicted concentration was within $10 \%$ of the measured. 


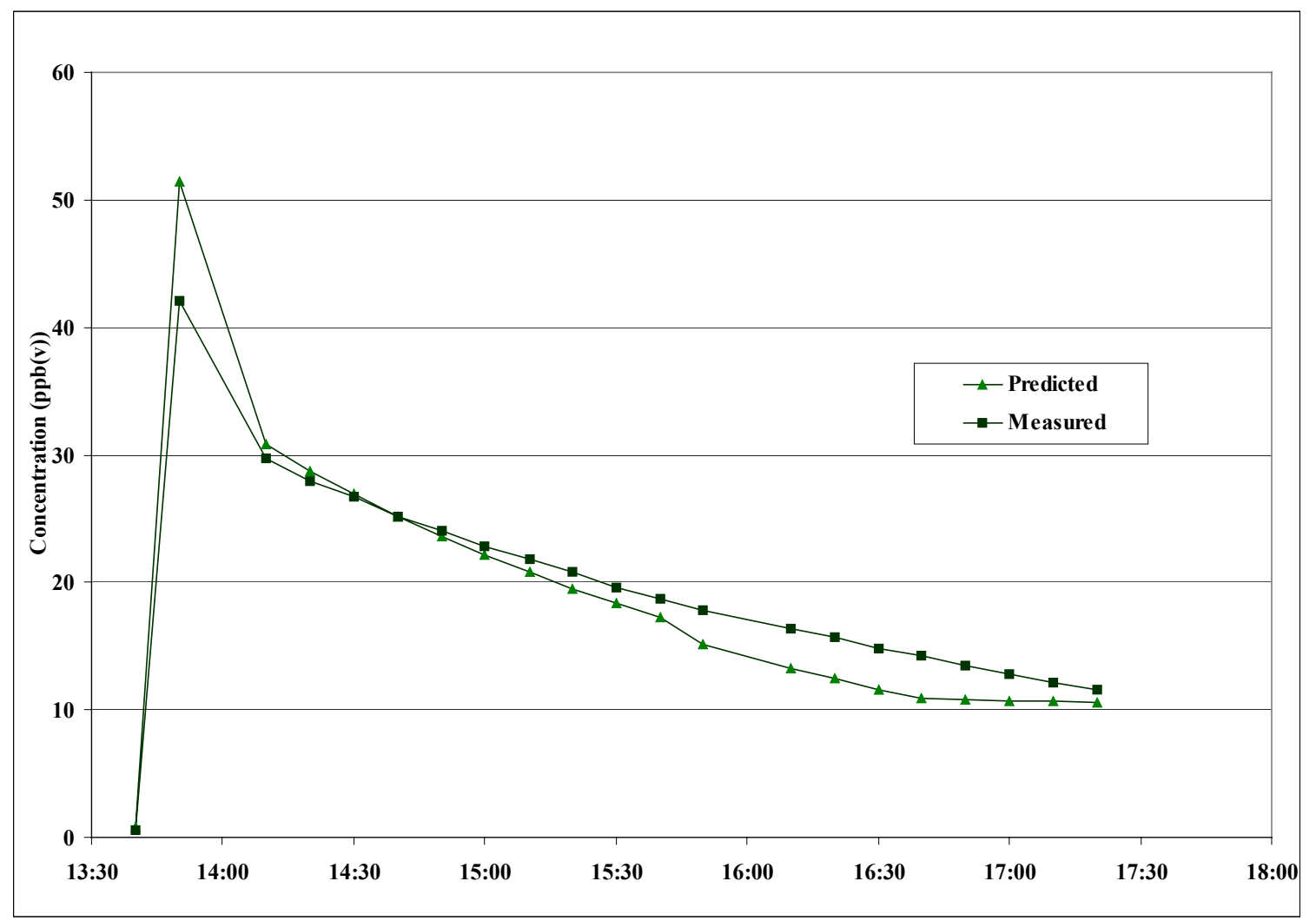

Figure 16 Measured and predicted concentrations in the HAC system return for Case \# 6

\section{Case \# 7}

Case \# 7 involved an injection in the REC zone with the HAC system operating during cold ambient conditions $\left(6.7^{\circ} \mathrm{C}\right)$. The measured and predicted transient zone concentrations are shown in Figure 17, and the D5157 statistical parameters are presented in Table 10. As for the other cases with the HAC system on, there was very good agreement between predictions and measurements for both individual zone transient concentrations and zone average concentrations. Just a few parameters fell outside the D5157 criteria and mostly not by much. As with Cases 4 and 6, Figure 18 shows that the predicted and measured concentrations in the HAC central return agreed very well, with a correlation coefficient of 1.0 and overall average predicted concentration exceeding measured by less than $10 \%$. 

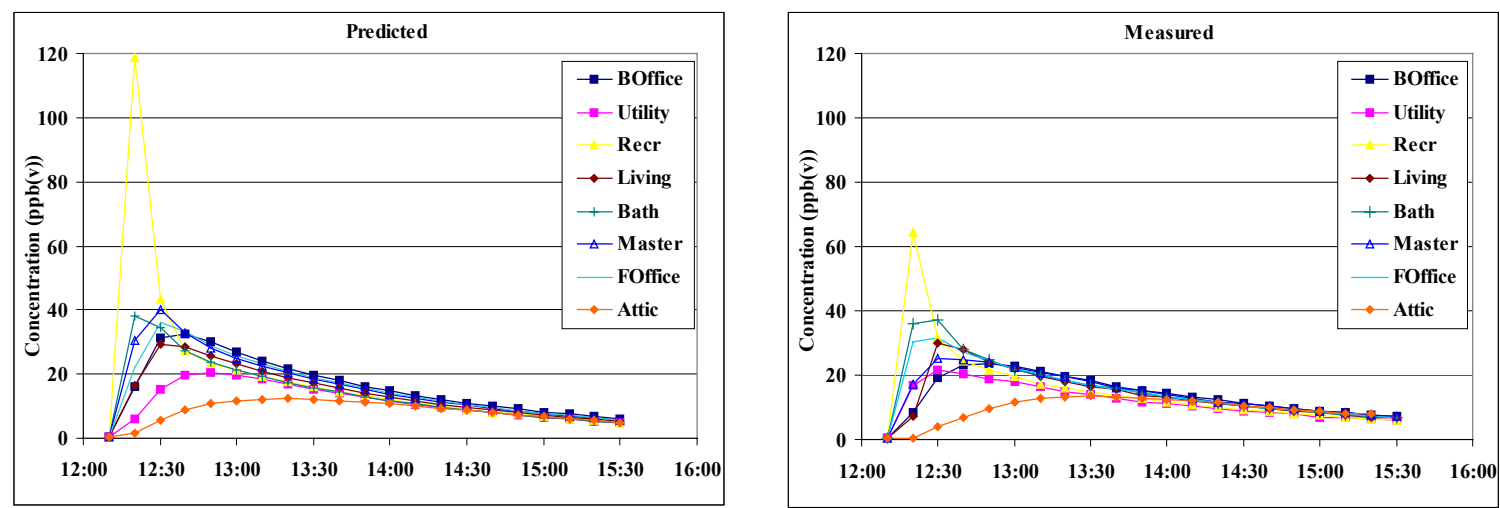

Figure 17 Predicted and measured $\mathrm{SF}_{6}$ concentrations for Case \# 7

Table 10 Statistical parameters for Case \# 7 (concentrations in ppb(v))

\begin{tabular}{|l|c|c|c|c|c|c|c|c|c|c|}
\hline Zone & $\mathbf{C}_{\mathbf{0}}$ & $\mathbf{C}_{\mathbf{p}}$ & $\sigma_{\mathbf{0}}$ & $\sigma_{\mathbf{p}}$ & $\mathbf{R}$ & $\mathbf{m}$ & $\mathbf{b} / \mathbf{C}_{\mathbf{0}}(\%)$ & $\mathbf{N M S E}$ & $\mathbf{F B}$ & $\mathbf{F S}$ \\
\hline REC (inj. zone) & 15.3 & 18.9 & 13 & 25 & $\mathbf{0 . 9 8}$ & 1.8 & -60 & 0.52 & $\mathbf{0 . 2 1}$ & 1.1 \\
\hline UTIL & 11.8 & 11.2 & 5.5 & 5.8 & $\mathbf{0 . 8 7}$ & $\mathbf{0 . 9 1}$ & $\mathbf{4 . 3}$ & $\mathbf{0 . 0 6}$ & $\mathbf{- 0 . 0 5}$ & $\mathbf{0 . 0 9}$ \\
\hline LR & 13.8 & 14.1 & 7.6 & 8.0 & $\mathbf{0 . 9 6}$ & $\mathbf{1 . 0}$ & 0 & $\mathbf{0 . 0 2}$ & $\mathbf{0 . 0 2}$ & $\mathbf{0 . 1 2}$ \\
\hline KDR & 12.1 & 14.3 & $*$ & $*$ & $*$ & $*$ & $*$ & $*$ & $*$ & $*$ \\
\hline MBR & 14.5 & 16.3 & 6.7 & 10 & $\mathbf{0 . 9 4}$ & 1.4 & $\mathbf{- 3 2}$ & $\mathbf{0 . 1 0}$ & $\mathbf{0 . 1 2}$ & 0.82 \\
\hline BOFC & 13.9 & 16.0 & 6.3 & 9.0 & $\mathbf{0 . 9 4}$ & 1.4 & $\mathbf{- 2 0}$ & $\mathbf{0 . 0 8}$ & $\mathbf{0 . 1 4}$ & 0.69 \\
\hline FOFC & 15.2 & 16.0 & 8.3 & 9.6 & $\mathbf{0 . 9 6}$ & $\mathbf{1 . 1}$ & $\mathbf{- 4 . 8}$ & $\mathbf{0 . 0 4}$ & $\mathbf{0 . 0 5}$ & $\mathbf{0 . 2 8}$ \\
\hline BATH & 15.7 & 14.4 & 9.5 & 10 & $\mathbf{0 . 9 9}$ & $\mathbf{1 . 0}$ & $\mathbf{- 1 2}$ & $\mathbf{0 . 0 1}$ & $\mathbf{- 0 . 0 8}$ & $\mathbf{0 . 0 9}$ \\
\hline ATC & 9.34 & 8.34 & 3.9 & 3.5 & $\mathbf{0 . 9 4}$ & $\mathbf{0 . 8 3}$ & $\mathbf{5 . 9}$ & $\mathbf{0 . 0 4}$ & $\mathbf{- 0 . 1 1}$ & $\mathbf{- 0 . 2 3}$ \\
\hline $\begin{array}{l}\text { Average } \\
\text { Concentrations }\end{array}$ & 13.5 & 14.5 & 2.1 & 3.1 & $\mathbf{0 . 8 6}$ & $\mathbf{1 . 3}$ & $\mathbf{- 2 1}$ & $\mathbf{0 . 0 2}$ & $\mathbf{0 . 0 6}$ & 0.74 \\
\hline
\end{tabular}

*KDR zone excluded from statistical analysis 


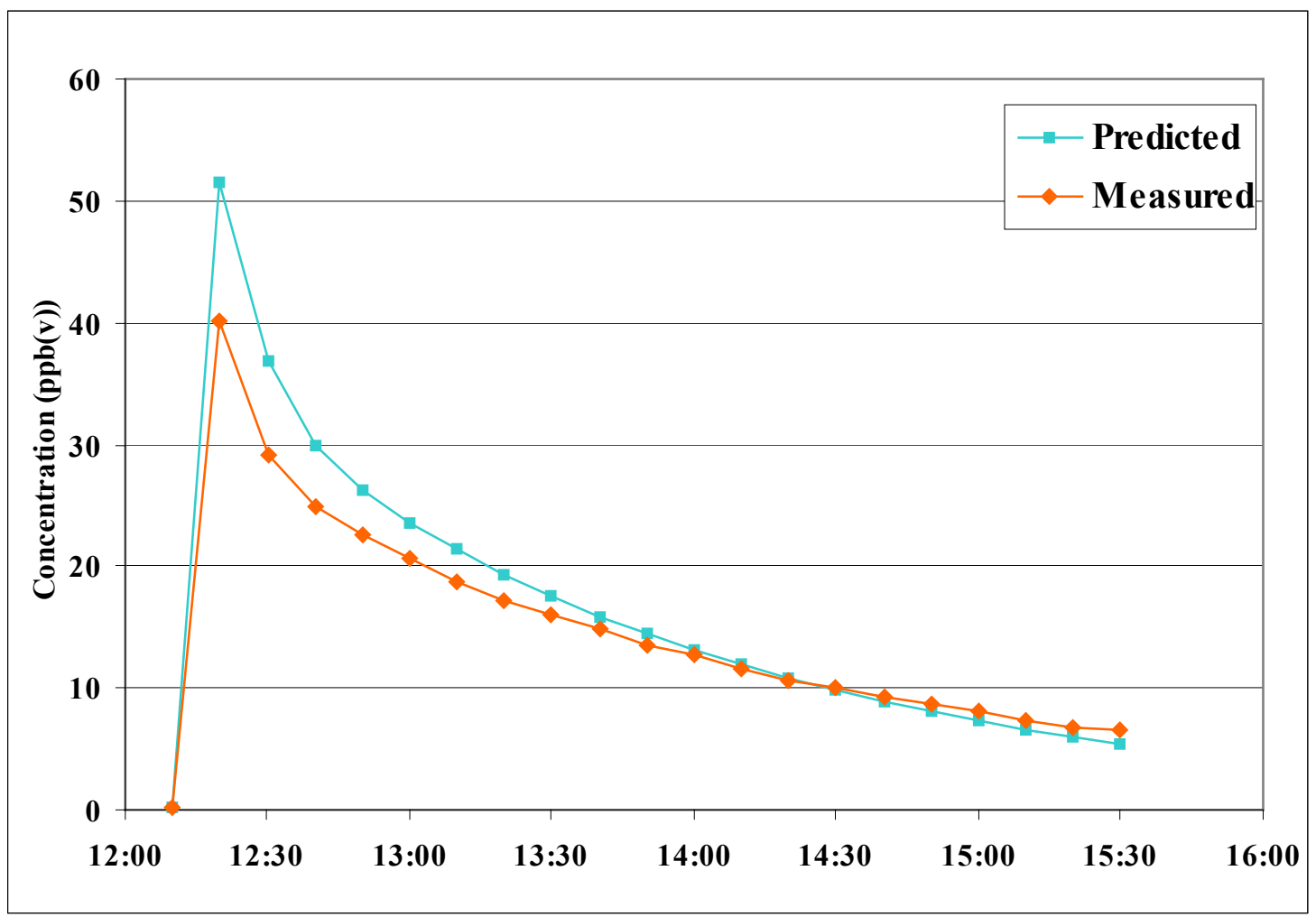

Figure 18 Measured and predicted concentrations in the HAC return for Case \# 7

Case \# 8

Case \# 8 involved an injection of $\mathrm{SF}_{6}$ in the MBR zone on the top floor of the townhouse with the HAC system fan off. The ambient conditions were mild with an average temperature of $14.5^{\circ} \mathrm{C}$ and an average wind speed of $2.3 \mathrm{~m} / \mathrm{s}$. Overall, the agreement between measured and predicted concentrations, shown in Figure 19 and Table 11, was good with a correlation coefficient between zone average concentrations of 0.96 . Many of the statistical parameters for both transient and average concentrations met the D5157 criteria, but concentrations were under-predicted in several zones with the predicted overall average concentration about $20 \%$ lower than the measured.
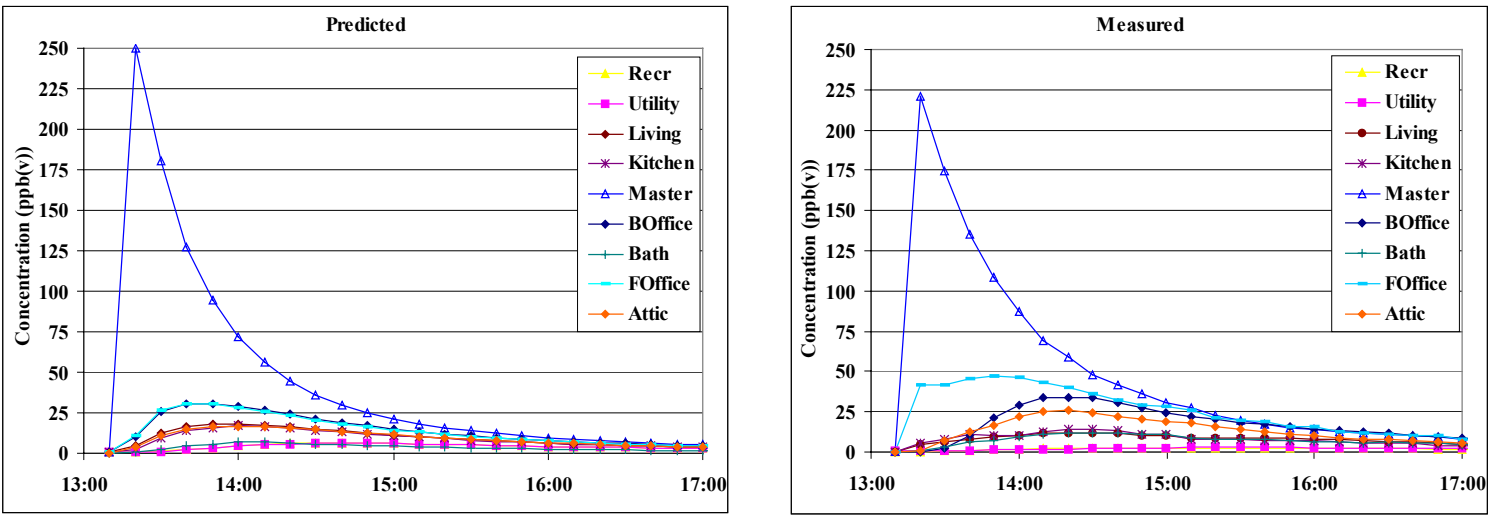

Figure 19 Predicted and measured $\mathrm{SF}_{6}$ concentrations for Case \# 8 
Table 11 Statistical parameters for Case \# 8 (concentrations in ppb(v))

\begin{tabular}{|l|c|c|c|c|c|c|c|c|c|c|}
\hline Zone & $\mathbf{C}_{\mathbf{0}}$ & $\mathbf{C}_{\mathbf{p}}$ & $\boldsymbol{\sigma}_{\mathbf{0}}$ & $\boldsymbol{\sigma}_{\mathbf{p}}$ & $\mathbf{R}$ & $\mathbf{m}$ & $\mathbf{b} / \mathbf{C}_{\mathbf{0}}(\mathbf{\%})$ & $\mathbf{N M S E}$ & $\mathbf{F B}$ & $\mathbf{F S}$ \\
\hline REC & 2.0 & 4.0 & 0.67 & 1.8 & 0.85 & 2.2 & $\mathbf{- 1 5}$ & 0.76 & 0.69 & 1.5 \\
\hline UTIL & 2.1 & 4.0 & 0.74 & 1.7 & 0.71 & 1.6 & 28 & 0.68 & 0.64 & 1.4 \\
\hline LR & 8.0 & 9.5 & 2.7 & 5.3 & 0.80 & 1.6 & -42 & $\mathbf{0 . 2 0}$ & $\mathbf{0 . 1 7}$ & 1.2 \\
\hline KDR & 8.1 & 8.8 & 3.5 & 4.9 & $\mathbf{0 . 9 3}$ & 1.3 & $\mathbf{- 1 8}$ & $\mathbf{0 . 0 7}$ & $\mathbf{0 . 0 9}$ & 0.62 \\
\hline MBR (inj. zone) & 48.0 & 42.6 & 57 & 61 & $\mathbf{0 . 9 9}$ & $\mathbf{1 . 1}$ & $\mathbf{- 1 8}$ & $\mathbf{0 . 0 5}$ & $\mathbf{- 0 . 1 2}$ & $\mathbf{0 . 1 5}$ \\
\hline BOFC & 17.2 & 14.0 & 10.3 & 9.3 & 0.56 & 0.50 & 31 & 0.40 & $\mathbf{- 0 . 2 1}$ & $\mathbf{- 0 . 2 0}$ \\
\hline FOFC & 24.8 & 13.7 & 14 & 9.2 & $\mathbf{0 . 9 4}$ & 0.60 & $\mathbf{- 4 . 5}$ & 0.50 & -0.57 & -0.85 \\
\hline BATH & 7.2 & 3.5 & 3.1 & 1.9 & $\mathbf{0 . 8 7}$ & 0.53 & $\mathbf{- 4 . 1}$ & 0.68 & -0.69 & -0.93 \\
\hline ATC & 13.1 & 9.2 & 7.5 & 4.9 & $\mathbf{0 . 9 0}$ & 0.58 & $\mathbf{1 3}$ & $\mathbf{0 . 2 5}$ & -0.35 & -0.82 \\
\hline $\begin{array}{l}\text { Average } \\
\text { Concentrations }\end{array}$ & 14.5 & 12.1 & 14 & 12 & $\mathbf{0 . 9 6}$ & $\mathbf{0 . 8 0}$ & $\mathbf{3 . 9}$ & $\mathbf{0 . 1 3}$ & $\mathbf{- 0 . 1 7}$ & $\mathbf{- 0 . 3 6}$ \\
\hline
\end{tabular}

Case \# 9

Case \# 9 also involved an injection in the MBR with the HAC system off but during very warm ambient conditions $\left(26.3^{\circ} \mathrm{C}\right.$ and $\left.1.2 \mathrm{~m} / \mathrm{s}\right)$. The measured and predicted transient zone concentrations are shown in Figure 20, and the D5157 statistical parameters are presented in Table 12. This case had very good agreement in terms of average concentrations as it met all D5157 criteria with the exception of a slightly high intercept. Case 9 was one of the few cases with higher overall average predicted concentration than measured. Once again, predicted concentrations in the BATH were low but the transient prediction correlated well with the measurement. Other individual zone transient concentration predictions ranged from fair to very good with the main issue being moderate over-prediction of the amount of $\mathrm{SF}_{6}$ moving down from the $3^{\text {rd }}$ floor to $2^{\text {nd }}$ and $1^{\text {st }}$ floors. 

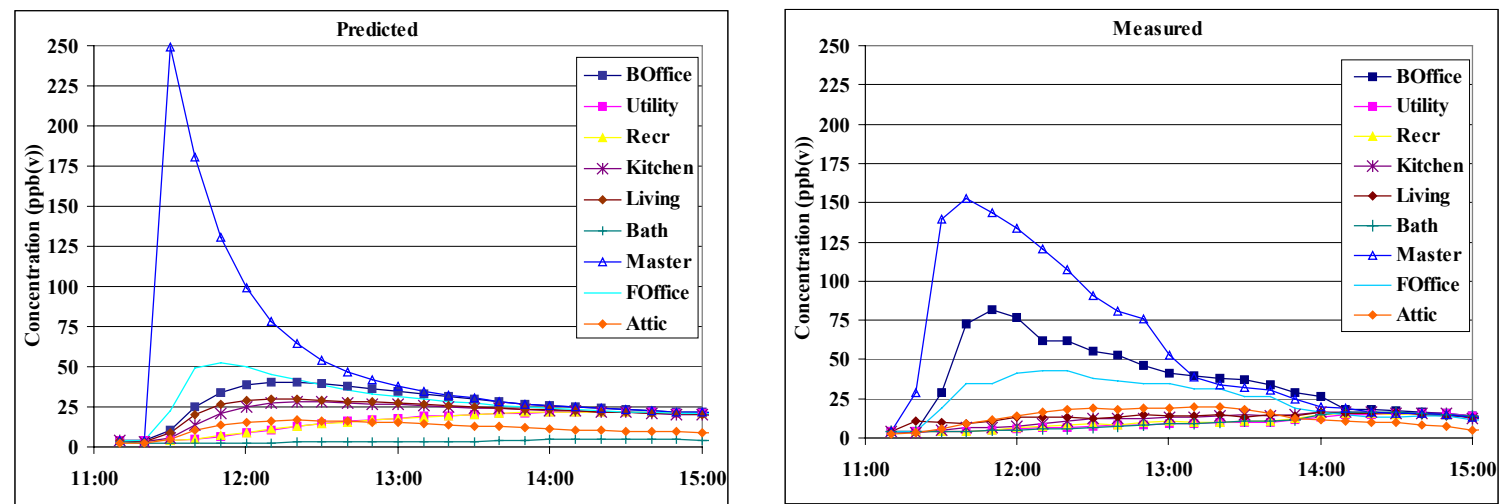

Figure 20 Predicted and measured $\mathrm{SF}_{6}$ concentrations for Case \# 9

Table 12 Statistical parameters for Case \# 9 (concentrations in ppb(v))

\begin{tabular}{|l|c|c|c|c|c|c|c|c|c|c|}
\hline Zone & $\mathbf{C}_{\mathbf{0}}$ & $\mathbf{C}_{\mathbf{p}}$ & $\boldsymbol{\sigma}_{\mathbf{0}}$ & $\boldsymbol{\sigma}_{\mathbf{p}}$ & $\mathbf{R}$ & $\mathbf{m}$ & $\mathbf{b} / \mathbf{C}_{\mathbf{0}}(\mathbf{\%})$ & $\mathbf{N M S E}$ & $\mathbf{F B}$ & $\mathbf{F S}$ \\
\hline REC & 10.1 & 15.7 & 4.0 & 9.3 & $\mathbf{0 . 9 4}$ & 1.6 & $\mathbf{0 . 8}$ & 0.27 & 0.44 & 1.4 \\
\hline UTIL & 9.6 & 15.8 & 4.1 & 6.7 & $\mathbf{0 . 9 0}$ & 1.5 & $\mathbf{1 6}$ & 0.34 & 0.48 & 0.91 \\
\hline LR & 13.2 & 22.3 & 2.7 & 7.2 & 0.60 & 1.6 & $\mathbf{8 . 9}$ & 0.42 & 0.52 & 1.5 \\
\hline KDR & 11.9 & 21.2 & 4.0 & 7.2 & 0.65 & $\mathbf{1 . 2}$ & 64 & 0.48 & 0.56 & 1.0 \\
\hline MBR (inj. zone) & 56.8 & 53.1 & 49 & 57 & 0.84 & $\mathbf{0 . 9 8}$ & $\mathbf{- 4 . 6}$ & 0.31 & $\mathbf{- 0 . 0 7}$ & $\mathbf{0 . 3 0}$ \\
\hline BOFC & 36.1 & 27.1 & 23 & 10 & 0.76 & 0.34 & 41 & 0.36 & -0.28 & -1.3 \\
\hline FOFC & 24.5 & 28.8 & 12 & 12 & $\mathbf{0 . 8 9}$ & $\mathbf{0 . 9 0}$ & 27 & $\mathbf{0 . 0 7}$ & $\mathbf{0 . 1 6}$ & $\mathbf{0 . 0 2}$ \\
\hline BATH & 9.6 & 3.6 & 4.4 & 0.9 & $\mathbf{0 . 9 4}$ & 0.19 & $\mathbf{1 8}$ & 1.5 & -0.92 & -1.8 \\
\hline ATC & 12.5 & 11.6 & 5.6 & 4.0 & $\mathbf{0 . 9 0}$ & 0.64 & 29 & $\mathbf{0 . 0 5}$ & $\mathbf{- 0 . 0 7}$ & -0.66 \\
\hline $\begin{array}{l}\text { Average } \\
\text { Concentrations }\end{array}$ & 20.5 & 22.1 & 16 & 14 & $\mathbf{0 . 9 1}$ & $\mathbf{0 . 7 8}$ & 30 & $\mathbf{0 . 1 0}$ & $\mathbf{0 . 1 1}$ & $\mathbf{- 0 . 3 0}$ \\
\hline
\end{tabular}

Case \# 10

The final test case was an injection in the MBR with the HAC system operating. Ambient conditions were warm $\left(21.6^{\circ} \mathrm{C}\right)$ with moderate wind $(2.5 \mathrm{~m} / \mathrm{s})$. The measured and predicted transient concentrations for each zone are shown in Figure 21. As seen in Table 13, this case showed good agreement for average zone concentrations with most D5157 criteria met (the slope and FS criteria were exceeded slightly). This case showed the greatest over prediction - about $25 \%$ on average. The length of this test was cut short due to the attic fan coming on at 15:00 (see below for a test case with the attic fan operating). Generally, a longer test will lead to better correlation for transient conditions. Also, the stack driving forces were minimal for this case, with only an average of $1{ }^{\circ} \mathrm{C}$ difference between indoor and outdoor temperatures. With that in mind, individual zone transient 
predictions compared fairly well to the measurements with $\mathrm{R}$ ranging from 0.66 to 0.96 . However, most zones had one or more parameter failing to meet the D5157 criteria.
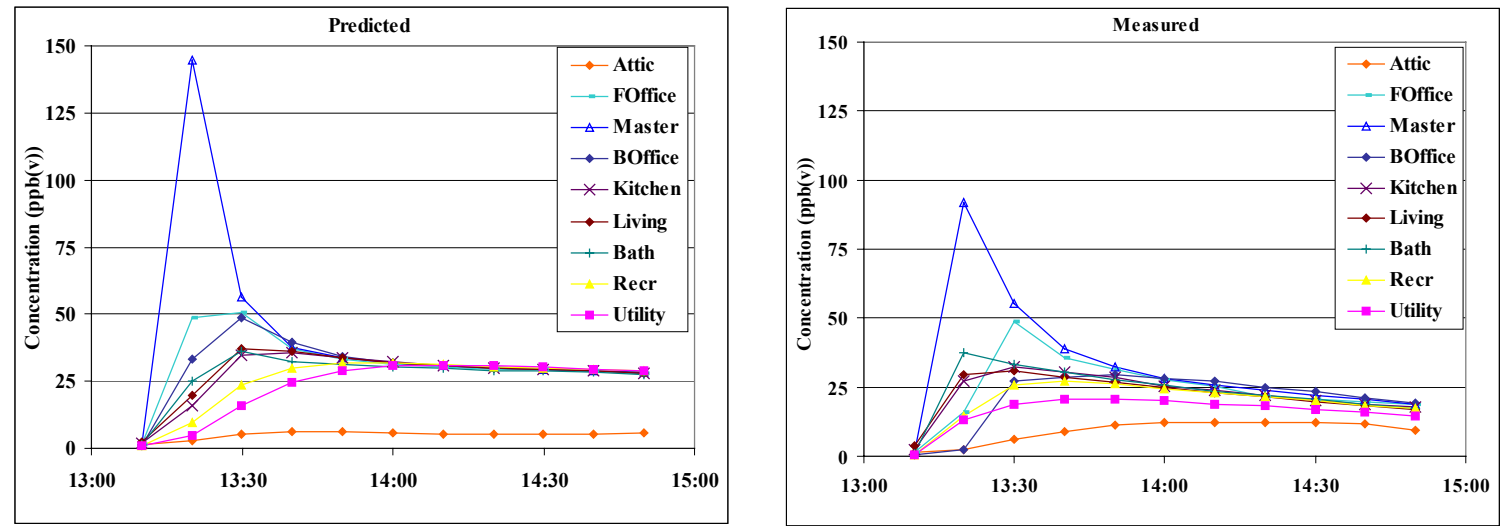

Figure 21 Predicted and measured $\mathrm{SF}_{6}$ concentrations for Case \# 10

Table 13 Statistical parameters for Case \# 10 (concentrations in ppb(v))

\begin{tabular}{|l|c|c|c|c|c|c|c|c|c|c|}
\hline Zone & $\mathbf{C}_{\mathbf{0}}$ & $\mathbf{C}_{\mathbf{p}}$ & $\sigma_{\mathbf{0}}$ & $\sigma_{\mathbf{p}}$ & $\mathbf{R}$ & $\mathbf{m}$ & $\mathbf{b} / \mathbf{C}_{\mathbf{0}}(\mathbf{\%})$ & $\mathbf{N M S E}$ & $\mathbf{F B}$ & $\mathbf{F S}$ \\
\hline REC & 19.9 & 25.2 & 7.6 & 10 & 0.85 & $\mathbf{1 . 1}$ & $\mathbf{1 2}$ & $\mathbf{0 . 1 1}$ & $\mathbf{0 . 2 4}$ & 0.60 \\
\hline UTIL & 16.2 & 23.3 & 5.8 & 11 & 0.75 & 1.4 & $\mathbf{- 1 . 8}$ & 0.28 & 0.36 & 1.1 \\
\hline LR & 22.1 & 28.0 & 7.7 & 9.6 & 0.78 & $\mathbf{0 . 9 8}$ & 28 & $\mathbf{0 . 1 1}$ & $\mathbf{0 . 2 3}$ & $\mathbf{0 . 4 5}$ \\
\hline KDR & 22.6 & 27.4 & $*$ & $*$ & $*$ & $*$ & $*$ & $*$ & $*$ & $*$ \\
\hline MBR (inj. zone) & 32.6 & 41.3 & 24 & 36 & $\mathbf{0 . 9 6}$ & 1.5 & $\mathbf{- 2 1}$ & $\mathbf{0 . 2 1}$ & $\mathbf{0 . 2 4}$ & 0.81 \\
\hline BOFC & 21.1 & 30.6 & 10 & 12 & 0.66 & $\mathbf{0 . 7 5}$ & 70 & $\mathbf{0 . 2 5}$ & 0.36 & $\mathbf{0 . 2 4}$ \\
\hline FOFC & 24.2 & 31.7 & 12 & 13 & 0.74 & $\mathbf{0 . 7 8}$ & 52 & $\mathbf{0 . 1 7}$ & 0.27 & $\mathbf{0 . 1 1}$ \\
\hline BATH & 23.4 & 27.3 & 9.7 & 9.1 & 0.78 & $\mathbf{0 . 7 3}$ & 44 & $\mathbf{0 . 0 8}$ & $\mathbf{0 . 1 5}$ & $\mathbf{- 0 . 1 4}$ \\
\hline ATC & 8.3 & 5.0 & 4.8 & 1.6 & 0.68 & 0.22 & 38 & 0.60 & -0.50 & -1.6 \\
\hline $\begin{array}{l}\text { Average } \\
\text { Concentrations }\end{array}$ & 20.9 & 26.5 & 6.9 & 10 & $\mathbf{0 . 9 6}$ & 1.4 & -16 & $\mathbf{0 . 0 8}$ & $\mathbf{0 . 2 3}$ & 0.74 \\
\hline
\end{tabular}

Note: For this case, the initial concentration for 3 zones was not measured prior to the injection. The average initial concentration of all other zones was used instead.

*KDR zone excluded from statistical analysis

Although the transient measured and predicted concentrations in the HAC central return showed good agreement (as shown in Figure 22), the agreement was not as good as the other HAC system on cases $(4,6$, and 7). However, the correlation coefficient was 0.88 and all parameters met the D5157 criteria. 


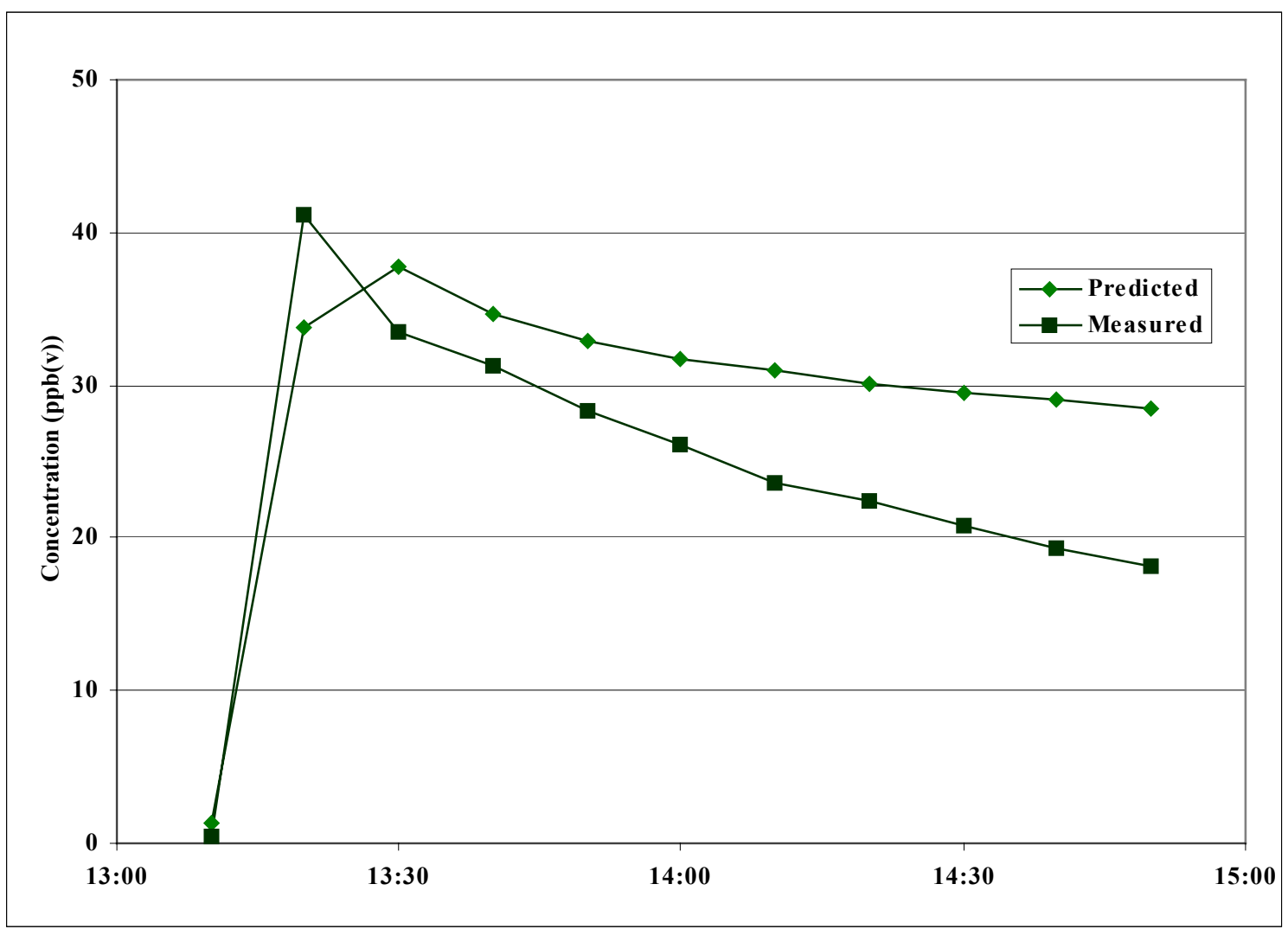

Figure 22 Measured and predicted concentrations in the HAC return for Case \# 10

\section{Summary}

Table 14 summarizes the statistical parameters calculated for all the cases based on the average zone concentrations. As seen in the table, the correlation coefficients range from 0.46 to 0.96 , with 6 of 10 cases at 0.9 or higher. As discussed for the individual cases, agreement for the first two cases suffers largely from significant under-prediction in the BATH zone. As expected, the agreement was consistently better for the cases with the $\mathrm{HAC}$ system operating, as the HAC flows are a significant driving factor in determining the zone concentrations. It was also no surprise that the case with the highest wind speed (Case \# 1) had the poorest correlation between measurements and predictions since past studies have reported poor agreement between measurements and predictions under high wind speed conditions as discussed earlier. 
Table 14 Summary of statistical parameters from comparison of average measured and predicted zone concentrations for all cases (concentrations in $\mathbf{p p b}(\mathrm{v})$ )

\begin{tabular}{|c|c|c|c|c|c|c|c|c|c|c|c|}
\hline Case & HAC & $\mathbf{C}_{\mathbf{0}}$ & $\mathbf{C}_{\mathbf{p}}$ & $\boldsymbol{\sigma}_{\mathbf{0}}$ & $\sigma_{\mathbf{p}}$ & $\mathbf{R}$ & $\mathbf{m}$ & $\mathbf{B} / \mathbf{C}_{\mathbf{0}}$ & $\mathbf{N M S E}$ & $\mathbf{F B}$ & $\mathbf{F S}$ \\
\hline 1 & Off & 26.6 & 21.0 & 19 & 13 & 0.46 & 0.31 & 48 & 0.54 & $\mathbf{- 0 . 2 4}$ & -0.73 \\
\hline 2 & Off & 32.2 & 25.0 & 12 & 8.4 & 0.81 & 0.57 & $\mathbf{2 0}$ & $\mathbf{0 . 1 2}$ & $\mathbf{- 0 . 2 5}$ & -0.67 \\
\hline 3 & Off & 18.9 & 16.4 & 10 & 7.6 & 0.56 & 0.41 & 45 & $\mathbf{0 . 2 4}$ & $\mathbf{- 0 . 1 4}$ & $\mathbf{- 0 . 5 2}$ \\
\hline 4 & On & 13.9 & 12.2 & 2.0 & 2.2 & $\mathbf{0 . 8 8}$ & $\mathbf{0 . 9 6}$ & $\mathbf{- 8 . 2}$ & $\mathbf{0 . 0 1 8}$ & $\mathbf{- 0 . 1 3}$ & $\mathbf{0 . 1 9}$ \\
\hline 5 & Off & 17.7 & 16.6 & 5.7 & 7.2 & 0.75 & $\mathbf{0 . 9 5}$ & $\mathbf{- 1 . 5}$ & $\mathbf{0 . 0 7}$ & $\mathbf{- 0 . 0 7}$ & $\mathbf{0 . 4 6}$ \\
\hline 6 & On & 17.9 & 16.7 & 2.5 & 3.2 & $\mathbf{0 . 9 6}$ & $\mathbf{1 . 2}$ & $\mathbf{- 3 2}$ & $\mathbf{0 . 0 1}$ & $\mathbf{- 0 . 0 7}$ & 0.51 \\
\hline 7 & On & 13.5 & 14.5 & 2.1 & 3.1 & $\mathbf{0 . 8 6}$ & $\mathbf{1 . 3}$ & $\mathbf{- 2 1}$ & $\mathbf{0 . 0 2}$ & $\mathbf{0 . 0 6}$ & 0.74 \\
\hline 8 & Off & 14.5 & 12.1 & 14 & 12 & $\mathbf{0 . 9 6}$ & $\mathbf{0 . 8 0}$ & $\mathbf{3 . 9}$ & $\mathbf{0 . 1 3}$ & $\mathbf{- 0 . 1 7}$ & $\mathbf{- 0 . 3 6}$ \\
\hline 9 & Off & 20.5 & 22.1 & 16 & 14 & $\mathbf{0 . 9 1}$ & $\mathbf{0 . 7 8}$ & 30 & $\mathbf{0 . 1 0}$ & $\mathbf{0 . 1 1}$ & $\mathbf{- 0 . 3 0}$ \\
\hline 10 & On & 20.9 & 26.5 & 6.9 & 10 & $\mathbf{0 . 9 6}$ & 1.4 & $-\mathbf{- 1 6}$ & $\mathbf{0 . 0 8}$ & $\mathbf{0 . 2 3}$ & 0.74 \\
\hline
\end{tabular}

The individual zone average concentrations from all cases are also plotted in Figure 23 to summarize the comparison of predictions and measurements (excluding the bath zone). The statistical parameters comparing measurements and predictions for this entire set of data do not quite meet the D5157 criteria as the correlation coefficient and slope are low and the intercept is slightly high. However, excluding the bathroom zone increases the correlation coefficient to 0.9 and brings all other parameters within the suggested values. In fact, excluding the single possible outlier point of the BATH zone from the first case increases the correlation coefficient to 0.85 and brings all other parameters except the slope (0.72) within the D5157 suggested criteria.

The predicted $\mathrm{SF}_{6}$ concentration averaged over all zones and cases (not weighted by zone volume) was within $10 \%$ of the average measured concentration. Excluding the bathroom zone, the overall average predicted concentration of $115 \mu \mathrm{g} / \mathrm{m}^{3}(19.3 \mathrm{ppb}(\mathrm{v}))$ was essentially identical to the overall average measured concentration of $116 \mu \mathrm{g} / \mathrm{m}^{3}$ (19.5 $\mathrm{ppb}(\mathrm{v}))$. 


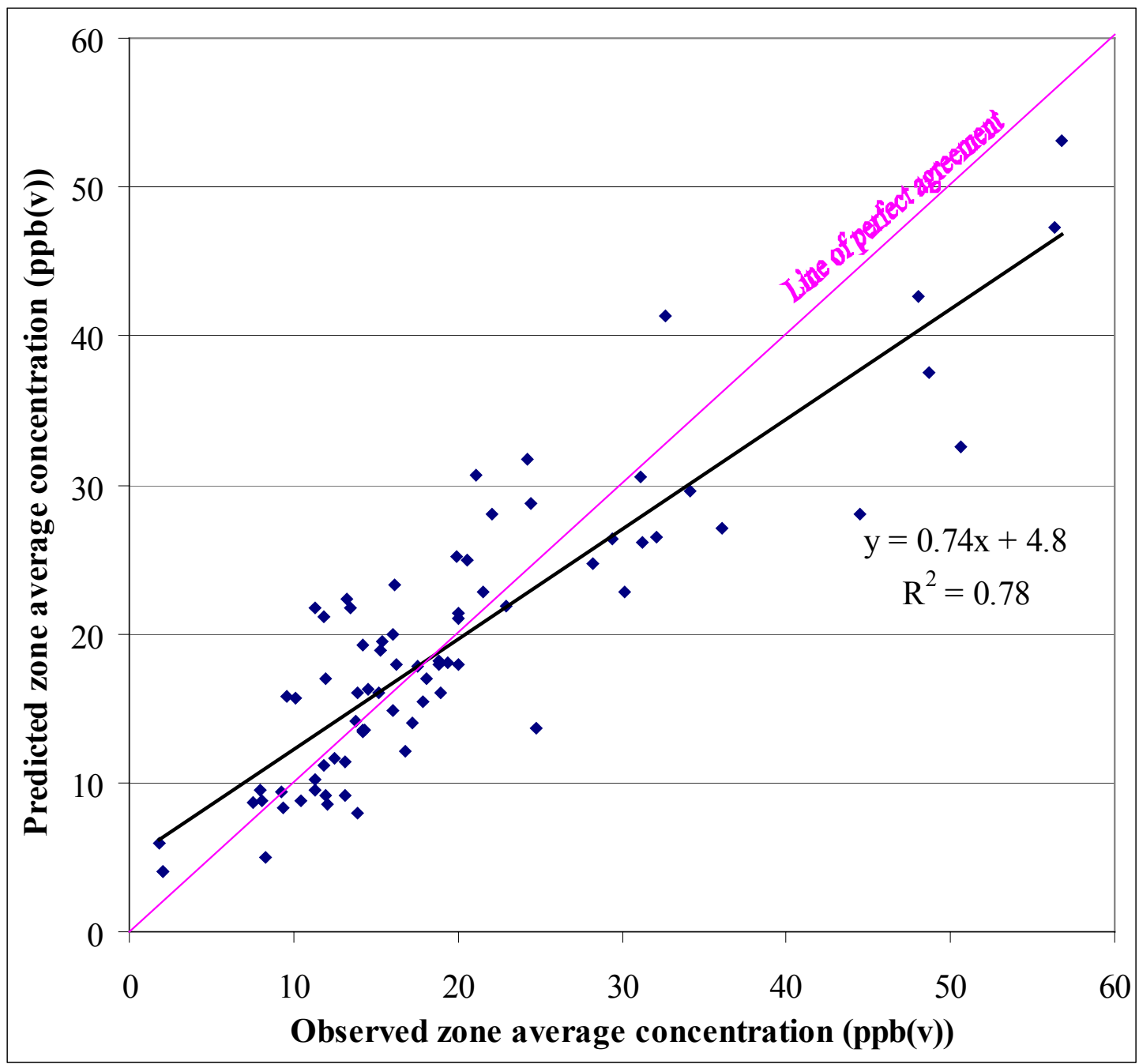

Figure 23 Comparison of predicted and measured zone average concentrations for all cases

\section{Attic Fan Case}

A common use of models like CONTAMW is to evaluate the impact of a change from a baseline case to another operating condition, such as the operation of a fan. As an additional challenge to the model, a test case was conducted during which an exhaust fan in the attic was operated. The attic fan exhausts air drawn from the attic to the outside. The fan flow was measured with the balometer to be $390 \mathrm{~L} / \mathrm{s}$. Other test conditions were similar to validation Case \# 5 described above: $1500 \mathrm{~mL}$ of $1 \% \mathrm{SF}_{6}$ was manually injected into the REC zone with the house HAC system off. Ambient conditions included an average temperature of $25^{\circ} \mathrm{C}$ and wind speed of $1.0 \mathrm{~m} / \mathrm{s}$. The measured and predicted (both without and with the attic fan in the model) transient zone concentrations are shown in Figure 24. The statistical parameters comparing the predictions (with attic fan) and measurements for both individual zone transient concentrations and overall zone average concentrations are presented in Table 15. As with several of the validation test cases, the agreement between predictions and measurements is good but not perfect as several zones fail to meet the ASTM criteria. However, if the modeler is interested in the relative impact of the attic fan (compared to the baseline case without it), the model does very 
well at predicting the impact on the concentrations with the attic fan operating over the 4 $\mathrm{h}$ test period (as shown in Figure 24).
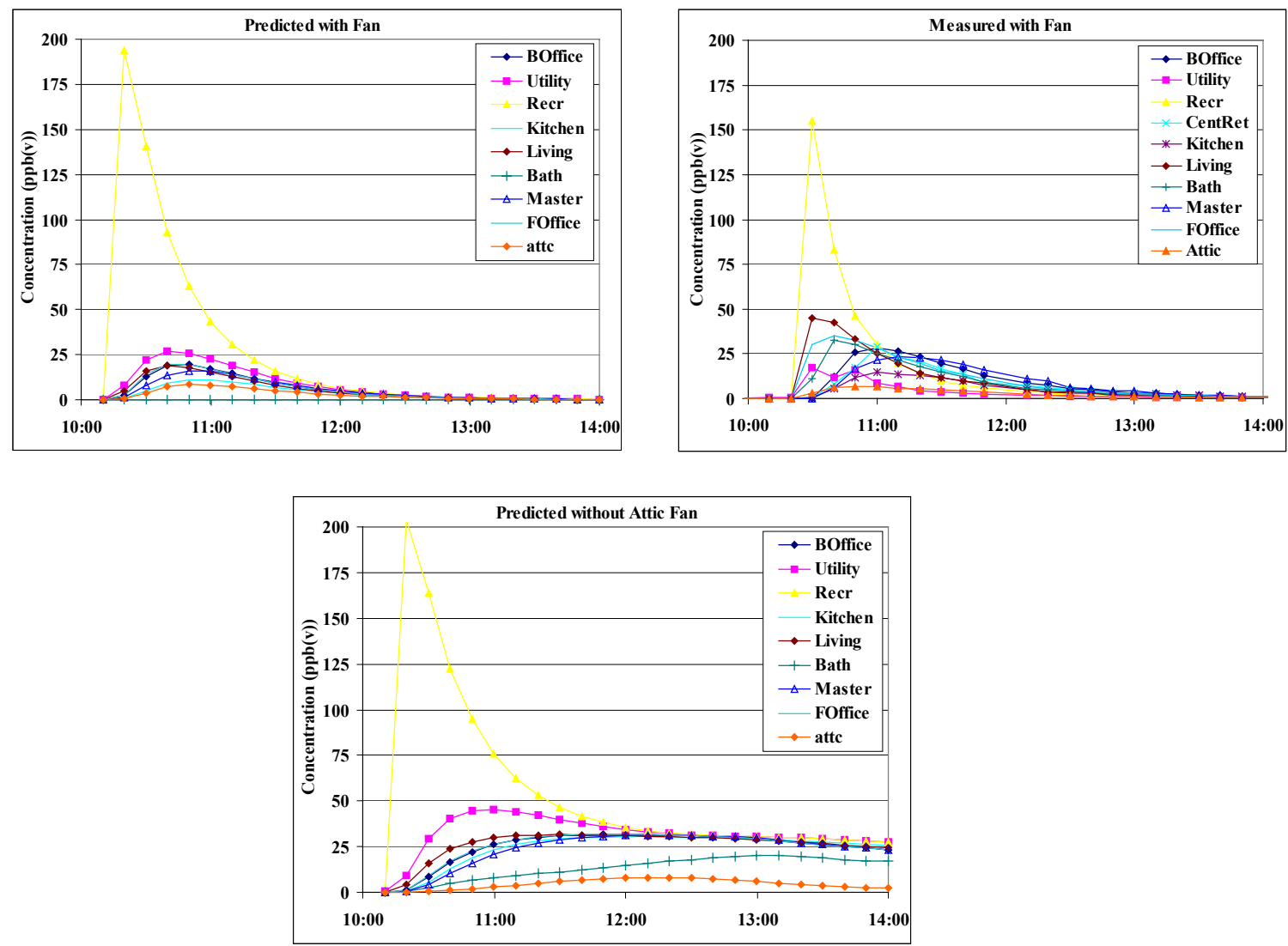

Figure 24 Predicted (with and without attic fan) and measured $\mathrm{SF}_{6}$ conc. for attic fan case

Table 15 Statistical parameters for attic fan test case

\begin{tabular}{|l|c|c|c|c|c|c|c|c|c|c|}
\hline \multicolumn{1}{|c|}{ Zone } & $\mathbf{C}_{\mathbf{0}}$ & $\mathbf{C}_{\mathbf{p}}$ & $\boldsymbol{\sigma}_{\mathbf{0}}$ & $\boldsymbol{\sigma}_{\mathbf{p}}$ & $\mathbf{R}$ & $\mathbf{m}$ & $\mathbf{b} / \mathbf{C}_{\mathbf{0}}(\mathbf{\%})$ & NMSE & $\mathbf{F B}$ & $\mathbf{F S}$ \\
\hline REC (inj. zone) & 16.5 & 27.0 & 35.1 & 49.4 & $\mathbf{0 . 9 8}$ & 1.4 & 26 & 0.89 & 0.48 & 0.66 \\
\hline UTIL & 3.7 & 8.0 & 4.9 & 9.0 & 0.73 & 1.4 & 81 & 2.0 & 0.73 & 1.09 \\
\hline LR & 9.9 & 5.4 & 13.4 & 6.3 & 0.76 & 0.36 & $\mathbf{1 9}$ & 2.1 & -0.58 & -1.28 \\
\hline KDR & 4.9 & 3.6 & 4.8 & 3.8 & $\mathbf{0 . 9 9}$ & $\mathbf{0 . 8 0}$ & $\mathbf{- 6 . 4}$ & $\mathbf{0 . 1 6}$ & -0.30 & $\mathbf{- 0 . 4 1}$ \\
\hline MBR & 8.4 & 5.2 & 8.3 & 5.5 & $\mathbf{0 . 9 6}$ & 0.64 & $\mathbf{- 2 . 3}$ & 0.52 & -0.48 & -0.77 \\
\hline BOFC & 8.8 & 5.8 & 9.4 & 6.6 & $\mathbf{0 . 9 8}$ & 0.68 & $\mathbf{- 3 . 3}$ & 0.41 & -0.42 & -0.69 \\
\hline FOFC & 10.2 & 5.7 & 11.5 & 6.6 & 0.85 & 0.48 & $\mathbf{7 . 8}$ & 1.2 & -0.56 & $\mathbf{- 1 . 0}$ \\
\hline BATH & 8.6 & 0 & $\mathrm{NA}$ & $\mathrm{NA}$ & $\mathrm{NA}$ & $\mathrm{NA}$ & $\mathrm{NA}$ & $\mathrm{NA}$ & $\mathrm{NA}$ & $\mathrm{NA}$ \\
\hline ATC & 2.5 & 2.7 & 2.2 & 2.8 & $\mathbf{0 . 9 3}$ & $\mathbf{1 . 2}$ & $\mathbf{- 1 0}$ & $\mathbf{0 . 1 9}$ & $\mathbf{0 . 0 6}$ & $\mathbf{0 . 4 6}$ \\
\hline $\begin{array}{l}\text { Average } \\
\text { Concentrations }\end{array}$ & 8.2 & 7.0 & 4.2 & 7.8 & 0.72 & $\mathbf{1 . 3}$ & -48 & 0.51 & $\mathbf{- 0 . 1 5}$ & 1.11 \\
\hline
\end{tabular}




\section{DISCUSSION}

It would be ideal if all the analyzed cases met all of the calculated statistical criteria for all variables. Conversely, it would be disappointing but straightforward if the model failed miserably when compared to measurements. However, even with either of these seemingly straightforward outcomes, the experimental validation results would still require interpretation. As discussed previously (Emmerich 2001), an absolute validation of a complex model, such as CONTAMW, is impossible as there are infinite possible building models that the user could create. If all the cases presented above met all the criteria, it could even lull users into a false sense of security of the model's capabilities since the success of any individual modeling effort depends largely on the user's knowledge of both the model and the building.

However, there are still important reasons to perform experimental validation such as to identify and eliminate large errors. For the situations modeled in this effort, no large errors in the CONTAMW model were identified. It is also important to remember that ASTM D5157 is a guideline not an ultimate arbiter of model accuracy. Rather than the specific parameters and criteria, its most valuable aspect may be to move model validation beyond the all too common and oversimplified analysis of "the measurements and predictions differed by $\mathrm{X} \%$ " and toward useful statistical analysis of model validation results.

Additionally, some of the discrepancies between model predictions and experimental measurements are due to experimental limitations instead of model deficiencies. For example, this effort involved a fairly rich data set in terms of number of variables monitored and spatial and temporal detail. Still, after completing the simulation effort, one can identify additional measurements that would have been desirable. Specifically, the halls and stairs of the townhouse provide the prime pathways for contaminant transport for cases without the HAC system operating - having temperature and concentration measurements in these important zones would have been valuable. Also, as previously discussed, inaccuracies in experimental measurements include much more than simply the instrument accuracy. All measurements reported here were a single point (occasionally chosen for reasons other than experimental accuracy) that was used to represent an average room concentration. The ability of this single point measurement to represent the room is certainly questionable shortly after a major system perturbation (i.e., a short duration tracer gas injection) or in the presence of continuous local disruption (i.e., location of a room sampling point in the path of ventilation supply air). Conduction of the experimental effort in an occupied home (although not occupied during the injection tests) presented the challenge of possessing less than complete control of the 'laboratory'.

The model, while quite detailed, could have been more so. The simple air-handling system option of CONTAMW was used rather than the detailed duct model option. While it is unlikely this modeling choice affected the HAC system-on cases, it may have 
affected the HAC system-off cases as the idle ducts can act as an important airflow pathways between zones that otherwise have little or no direct communication. Additionally, some of the cases may have been affected by the CONTAMW 1.0 limitation of constant zone temperatures. While the interior temperature for most zones was stable during most tests, there were situations such as the second test case when the temperature difference between the $3^{\text {rd }}$ floor and the attic ranged from $2^{\circ} \mathrm{C}$ to $5^{\circ} \mathrm{C}$ during the test. It would be interesting to repeat simulations for selected cases with the newest version of CONTAMW 2.0, which includes the capability of varying zone temperatures.

Finally, it is not necessary for this model evaluation to stand entirely on its own. Rather, it should be considered in the context of the existing body of work validating CONTAMW and similar models. Emmerich (2001) reviewed ten such efforts that have been reported in the literature. This effort differs from others reported primarily in number of variables monitored, number of cases analyzed, and execution of experimental effort in an occupied home. In the end, the results reported here echo those summarized in the earlier review: a knowledgeable user can expect to make reasonable predictions of air change rates, interzonal flows, and contaminant concentrations for residential-scale buildings dominated by stack-driven or ventilation flows with inert pollutants. Areas identified previously as needing more work, such as large buildings, wind-driven flows, reactive contaminants, small time scales, and non-trace contaminants were not addressed in this study. Some of these needs are being addressed by ongoing research at NIST. 


\section{CONCLUSION}

The primary objective of this effort was to evaluate the capability of the multizone IAQ model CONTAMW to simulate tracer gas concentrations in a real multizone building subject to real ambient conditions. Predictions of $\mathrm{SF}_{6}$ concentrations were compared to measurements for eleven test injection cases with statistical analysis performed per ASTM Guide D5157. Overall, the comparison between predictions and measurements of average zone concentrations was good implying the adequacy of CONTAMW to predict average contaminant concentrations in residential buildings under real world conditions.

A single zone - the main floor bathroom - accounted for most significant discrepancies between measurements and predictions of zone average concentrations. Several potential causes of the consistent under-prediction of tracer gas transport into this zone were identified including wind speed and direction, envelope leakiness, and small temperature differences relative to the adjacent zone. However, with the removal of this zone, the predicted values fell well within the suggested guidelines. In most cases, the average zone concentrations were under-predicted, but remained within $10 \%$ of the measured values. Thus, the poor predictions for this particular zone did not affect the accuracy of the prediction concentrations throughout the rest of the house.

Although individual zone transient concentration comparisons were not always good, the majority had correlation coefficients of at least 0.8 and many were much higher. Again, the bathroom zone was the only zone with frequent discrepancies in transient concentration predictions while other zone predictions experienced only sporadic discrepancies.

A secondary objective of the validation effort was to identify any large shortcomings in the model, which may be overcome through modifications to the model. However, this validation effort did not identify any needed modifications to the CONTAMW model. 


\section{ACKNOWLEDGEMENTS}

The authors wish to acknowledge the efforts of Stuart Dols and Kevin Blank in support of this project. 


\section{REFERENCES}

ASHRAE. Practices for Measurement, Testing, Adjusting and Balancing of Building Heating, Ventilation, Air-Conditioning and Refrigeration Systems ASHRAE Standard 111 (1988) American Society of Heating, Refrigerating and Air-Conditioning Engineers, Inc.

ASHRAE. Handbook of Fundamentals. (1997) American Society of Heating, Refrigerating and Air-Conditioning Engineers, Inc.

ASTM. Standard Guide for Statistical Evaluation of Indoor Air Quality Models. D515791 (1997) American Society for Testing and Materials.

ASTM. Standard Test Method for Determining Air Change in a Single Zone by Means of a Tracer Gas Dilution. E741-95 (2000) American Society for Testing and Materials.

ASTM. Standard Test Method for Determining Air Leakage Rate by Fan Pressurization. E779-99 (1999) American Society for Testing and Materials.

Bassett M. Infiltration and leakage paths in single family houses - a multizone infiltration case study. (1990) AIVC Technical Note 27, Air Infiltration and Ventilation Centre.

Dols WS, Walton GN, and KR Denton. CONTAMW 1.0 User Manual (2000) NISTIR 6476, National Institute of Standards and Technology.

Dols WS and Walton GN. CONTAMW 2.0 User Manual (2002) NISTIR 6921, National Institute of Standards and Technology.

Emmerich SJ and Nabinger SJ. Measurement and Simulation of the IAQ Impact of Particle Air Cleaners in a Single-Zone Building. (2001) International Journal of HVAC\&R Research Vol. 1, No. 7, ASHRAE.

Emmerich SJ. "Validation of Multizone IAQ Modeling of Residential-scale Buildings: A Review" (2001) ASHRAE Transactions Vol. 107.2.

Wallace LA, Emmerich SJ, and Howard-Reed C. "Continuous measurements of air change rates in an occupied home for 1 year: The effect of temperature, wind, fans, and windows" (2002) Journal of Exposure Analysis and Environmental Epidemiology Vol. 12 . 